\title{
Español con (otros) sonidos araucanos: la influencia del mapudungun en el sistema vocálico del castellano chileno
}

\author{
Scott Sadowsky ${ }^{1}$ \\ Pontificia Universidad Católica de Chile, Chile \\ Max Planck Institute for the Science of Human History, Alemania
}

\begin{abstract}
Resumen
El presente artículo examina la posible influencia del mapudungun, la lengua indígena más hablada de Chile, en el castellano chileno, desde dos perspectivas. En primer lugar, reexaminamos la hipótesis que el lingüista alemán Rodolfo Lenz desarrolló a fines del siglo XIX. Ésta postula que una serie de 10 rasgos fonéticos y fonológicos del castellano de Chile provendrían del mapudungun. Analizamos cada uno de estos rasgos, revisando críticamente los argumentos de Lenz y de su principal detractor, el filólogo peninsular Amado Alonso, a la luz de los conocimientos contemporáneos de la lingüística, la genética, la demografía y otras disciplinas. Concluimos que es improbable o imposible que tres de los rasgos se hayan originado en el mapudungun; que tres otros rasgos probablemente sí fueron transferidos desde el mapudungun al castellano de Chile; y que la falta de estudios relevantes impide llegar a una conclusión fundada en
\end{abstract}


los demás casos. En segundo lugar, presentamos los resultados de un estudio que analiza las vocales del castellano de Chile, comparándolas con las vocales del mapudungun y las de otras variedades del castellano. Las vocales, que la hipótesis de Lenz no contempla, se analizan en términos de su ubicación (timbre o cualidad) y del tamaño del sistema que conforman en el espacio acústico. Los resultados indican que las vocales del castellano de Chile y las del mapudungun son fuertemente medio-centralizadas y que ocupan una proporción menor del espacio acústico, mientras que las vocales de las demás variedades del castellano son casi sin excepción periféricas y ocupan la mayor parte del espacio acústico disponible. Concluimos que es probable que el sistema vocálico del castellano chileno se haya reorganizado bajo la influencia del mapudungun.

Palabras clave: vocales, contacto lingüístico, español chileno, mapudungun, fonética, fonología, Rodolfo Lenz.

\title{
Spanish With (DiffERent) Araucanian Sounds: \\ The Influence of Mapudungun on the ChILEAN SPANish VOWEL SYSTEM
}

\begin{abstract}
This paper investigates the possible influence of Mapudungun, Chile's most widely-spoken indigenous language, on Chilean Spanish, using a two-pronged approach. First, we reexamine German linguist Rudolf Lenz's late nineteenth-century hypothesis that a series of phonetic and phonological features of Chilean Spanish originated in Mapudungun. We analyze each of the 10 features that Lenz proposed to be of Mapuche origin, critically review his arguments and those of his main detractor, Spanish philologist Amado Alonso, and then examine these proposals in light of contemporary linguistic, genetic, demographic and other knowledge. We conclude that three of the features Lenz attributed to Mapudungun either cannot have originated in this language or are highly unlikely to have done so, while three others very likely were transferred from Mapudungun to Chilean Spanish, and that the remaining four must be studied more extensively before conclusions are drawn. Second, we present the results of a study which examines Chilean Spanish vowels and compares them with those of Mapudungun and of other varieties of Spanish. The vowels, which Lenz did not consider in his hypotheses, are analyzed in terms of both their location (or quality) and the size of the systems they constitute in acoustic space. The results show that the vowels of both Chilean Spanish and Mapudungun are strongly mid-centralized and use little acoustic space, while those of other Spanish varieties are
\end{abstract}


almost without exception peripheral and occupy most of the available acoustic space. We conclude that the Chilean Spanish vowel system was likely reorganized under the influence of Mapudungun.

Keywords: Vowels, language contact, Chilean Spanish, Mapudungun, phonetics, phonology, Rudolf Lenz.

Recibido: $13 / 05 / 19 \quad$ Aceptado: 08/10/20

\section{INTRODUCCIÓN ${ }^{2}$}

\subsection{LAS PARTICULARIDADES DEL CASTELLANO DE CHILE Y LA TESIS INDIGENISTA DE LENZ}

En la dialectología hispánica, el castellano de Chile representa una variedad de la lengua particularmente distintiva, constituyendo una zona propia en la mayoría de las propuestas de clasificación (Lipski 1994). El hecho de que no trascienda ninguna frontera nacional -como sí sucede con el castellano rioplatense, andino y caribeño, entre otros- se debe principalmente a las barreras geográficas que históricamente han aislado a Chile de sus vecinos. Dicho aislamiento se vio reforzado, además, por la marginalidad de Chile dentro del imperio español, donde fue una mera capitanía general, sin grandes riquezas ni otros atractivos para la corona española.

Si bien el aislamiento no genera cambios lingüísticos, como a veces se piensa, sí favorece la retención de los cambios que surgen más o menos aleatoriamente en toda lengua, al reducir o eliminar los procesos de ajuste, nivelación y convergencia que el contacto suele producir. En este contexto, no resulta en absoluto sorprendente que el castellano de Chile haya divergido de manera tan profunda de los demás geolectos del español. El plano léxico ofrece el ejemplo más fácilmente cuantificable de esta realidad: los 10 volúmenes del Diccionario ejemplificado de chilenismos de Félix Morales

\footnotetext{
2 La presente investigación fue patrocinada por CONICYT Chile mediante el proyecto FONDECYT de Iniciación No 11150900, Huellas del contacto: El impacto del mapudungun en la conformación del sistema fonético-fonológico del castellano de Chile. Una versión preliminar de parte de este artículo se presentó en el IV Congreso Internacional de Lenguas y Literaturas Indoamericanas y XV Jornadas de Lengua y Literatura Mapuche, Temuco, Chile, en noviembre de 2012.
} 
Pettorino y colaboradores (Morales Pettorino, Quiroz y Peña Álvarez 1984, 1985, 1986, 1987, 1998, Morales Pettorino, Quiroz, y Arancibia 2006a, 2006b, 2006c, Morales Pettorino y Quiroz 2010a, 2010b) contemplan nada menos que 11.322 páginas de términos y acepciones que, en su gran mayoría, no figuran en el diccionario de la Real Academia Española. En el plano fonético, el castellano chileno también se muestra propenso a la diversidad, registrando por lo menos 93 alófonos consonánticos distintos (Sadowsky y Salamanca 2011), además de una rica y compleja alofonía vocálica que se correlaciona con el acento léxico, el sexo y el estrato socioeconómico de los hablantes (Sadowsky 2016). Otros niveles lingüísticos también manifiestan fenómenos poco frecuentes o desconocidos fuera de Chile, como es el caso de la (auténtica) reduplicación de clíticos (Silva-Corvalán 2001) ${ }^{3}$, el voseo chileno (Rivadeneira 2009) y la fusión parcial de los $2^{\circ}$ y $3^{\circ}$ paradigmas verbales (e.g. tenimos que comer mejor), por nombrar solo algunos ejemplos.

Ya a fines del siglo XIX, el lingüista alemán Rudolf (Rodolfo) Lenz (1863-1938) repara en la naturaleza particular del castellano de Chile, aseverado que "el español ha evolucionado probablemente en Chile más que en ninguna nación de la tierra y es de un extraordinario interés fonético debido a sus originales peculiaridades de pronunciación" (1940a). Esta afirmación se basa principalmente en una serie de 10 rasgos fonéticofonológicos que Lenz considera propios de esta variedad de la lengua, y que se examinan en detalle en el apartado 1.3.

Para explicar el origen de estos fenómenos, Lenz desarrolla la llamada tesis indigenista, la cual postula que gran parte de las particularidades fonético-fonológicas del castellano chileno -especialmente las del estrato socioeconómico bajo- se habrían originado en el mapudungun (Lenz 1912, 1940a, 1940b). Al respecto, Lenz señala lo siguiente: "Si ahora comparamos la fonética del habla chilena [...] con la araucana [mapuche], aparecen [...] tantos puntos de contacto entre ambas lenguas, que creo lícito atribuir la evolución peculiar del español de Chile precisamente a la influencia de este estrato araucano subyacente" (1940b). Esta idea queda resumida aún más escuetamente en la famosa aseveración de que el español del "pueblo bajo" de Chile sería "principalmente español con sonidos araucanos [mapuches]" (Lenz 1940b).

\footnotetext{
3 Este fenómeno, que implica la repetición de un mismo clítico (e.g. te voy a llamarte), no debe confundirse con otro que recibe el mismo nombre, pese a que no involucra reduplicación alguna, sino el uso correferencial de un clítico y un pronombre (e.g. te voy a llamar a ti). Este último fenómeno se observa a lo largo del mundo hispanoparlante, al contrario de la reduplicación de clíticos en sentido estricto, que parece limitarse a Chile.
} 


\subsection{LA REACCIÓN DEL ESTABLISHMENT HISPANISTA}

La reacción que suscita la tesis indigenista en la mayor parte de los filólogos y lingüistas españoles e hispanoamericanos de la época es de rechazo absoluto (cf., entre otros, Cuervo 1901; Menéndez Pidal 1918; Castro 1924; Rosenblat 1945; Menéndez Pidal 1947; Alonso 1953c, 1953a, 1953b, 1967). El caso de Amado Alonso, quizás el máximo exponente del anti-indigenismo, es ilustrativo: lleva a cabo una intensa campaña para desacreditar las ideas de Lenz, traduciendo o reeditando gran parte de las obras juveniles del lingüista alemán con la finalidad de "acusarlas de falaces" y, de este modo, neutralizar no solo la tesis indigenista, sino también las demás ideas de Lenz que atentan contra los axiomas del hispanismo ortodoxo: el descriptivismo, el rechazo de la primacía lingüística de España y la negación de la unidad esencial del castellano, principalmente (Bernaschina 2013).

En este contexto, Alonso argumenta en contra del origen mapuche de cada uno de los 10 rasgos fonéticos o fonológicos que Lenz señala como provenientes del mapudungun; solamente admite la posibilidad de que determinados lexemas y -posiblemente- algún rasgo de la entonación chilena tengan origen indígena. No es casual que la variación de estos últimos elementos no represente amenaza alguna para la unidad hegemónica que Alonso predica, por tratarse de fenómenos asistemáticos (el léxico) o incluso "folklóricos" (la entonación, o "cantadito" como muchos hablantes le llaman), y por ende ajenos al sistema lingüístico.

En cuanto a los mecanismos de transmisión que propone Lenz, Alonso niega que haya existido más que un mínimo nivel de mestizaje en el centro de Chile, aseverando que "[e]n la zona central, región de Santiago y Valparaíso, la población es blanca, con muy pocos mestizos que no sean de reciente incorporación" (1953b: 283). A la vez, insiste en que lo determinante en la conformación de las lenguas no es el proceso de adquisición que se produce durante la infancia y juventud, sino la decisión consciente del hablante adulto de serle fiel al ideal espiritual de la lengua. Según esta lógica, aunque hubiera existido un prolongado e intenso contacto entre hispano-chilenos y mapuches -con o sin mestizaje de por medio-, la situación no habría generado cambios en el castellano de Chile, según Alonso, por no haber sido dignos de imitación "quienes hablan el idioma chapuceramente y como extranjeros" (1953b: 284), es decir, los mapuches. Estos argumentos se analizan detalladamente en el apartado 4.4.2.

La campaña de desprestigio que llevó a cabo Alonso fue sumamente exitosa. Tanto así, que hasta el día de hoy la inexistencia de cualquier influencia indígena sistemática en el español constituye un artículo de fe del hispanismo. La idea de que el tema está zanjado y, por ende, no merece 
ser investigado, se impuso con una fuerza que excede en varios órdenes de magnitud la calidad de los argumentos del filólogo peninsular.

Las pocas veces que se ha mencionado la posibilidad de una influencia indígena en el castellano desde ese entonces, ha sido casi siempre de manera superficial y con el único fin de expresar acuerdo con los juicios de Alonso, sin aportar datos, análisis ni argumentos propios (Oroz 1966; Hernández 1981; Contreras 1989; Salas 1992; Valencia 1993; Salas 1996; Rabanales 2002). Valencia ejemplifica esta tendencia, tanto por la brevedad de su tratamiento del tema, como por su presentación tajante, la cual no da lugar a sutilezas ni cuestionamientos: "Esta tesis [...] fue objeto de un examen crítico por Amado Alonso (1953) y refutada en todas sus partes" (1993).

Uno de los pocos estudiosos que examinó la tesis indigenista nuevamente, en vez de limitarse a repetir acríticamente las opiniones de Alonso, fue Adalberto Salas. Pero lejos de reivindicarla, Salas lleva algunas de las ideas de Alonso a un nuevo extremo. Niega, por ejemplo, la existencia de un mestizaje más que fortuito no solo en la zona central de Chile, sino en todo el país: "Frente a las circunstancias, el solo sentido común sugiere que mestizaje debió haber [en Chile] (¿por qué no?), pero debió ser ocasional y esporádico, tanto que no alcanzó a afectar la lengua y la cultura de la comunidad como un todo" (1992).

A la luz de todo lo anterior, no resulta sorprendente que sean casi inexistentes los estudios modernos de la posible influencia del sustrato indígena. Uno de los objetivos del presente artículo, más allá de explorar un determinado fenómeno lingüístico, es el de mostrar que lejos de ser un tema resuelto, la posibilidad de que el mapudungun haya incidido en el castellano chileno merece ser investigada a fondo, con todas las herramientas teóricas y técnicas de que dispone la ciencia lingüística moderna.

\subsection{LA TESIS INDIGENISTA ANALIZADA DESDE LA LINGÜÍSTICA MODERNA}

Lenz se basa en un conjunto de 10 fenómenos para argumentar que el sistema fonético-fonológico de los estratos socioeconómicos bajos de Chile experimentó una fuerte influencia de parte del mapudungun. A continuación, éstos se examinarán uno por uno, a la luz del estado del arte del conocimiento lingüístico. Los fenómenos en cuestión son los siguientes ${ }^{4}$ :

4 La terminología y los símbolos fonéticos utilizados por Lenz, Alonso y los demás autores citados en el presente artículo han sido modernizados. 
(1) Debucalización ("aspiración") $(\rightarrow[\mathrm{h}])$ o elisión $(\rightarrow \varnothing)$ de $/ \mathrm{s} /$ en coda silábica.

(2) Espirantización de las oclusivas sonoras (/b, d, g/ $\rightarrow[\beta, \partial, \gamma])$.

(3) Velarización $(\rightarrow[\mathrm{g}, \mathrm{\gamma}])$ o vocalización $(\rightarrow[\mathrm{i}])$ de /d/ ante / $/$ / en palabras como padre (['pa.yre], ['pai.re]).

(4) Conservación de $/ K /$.

(5) Realización bilabial de /f/ $(\rightarrow[\Phi])$.

(6) Realización lámino-alveolar de /t $, \mathrm{d}, \mathrm{s} / \operatorname{tras} / \mathrm{f} /(\rightarrow[\mathrm{t}, \mathrm{d}, \mathrm{s}])$.

(7) Alta frecuencia del fonema $/ \widehat{t} \int /$ en hipocorísticos y otras palabras familiares.

(8) Realización fricativa ("asibilada" en la terminología de la época) de $/ \mathrm{r} /(\rightarrow[\check{\mathrm{x}}, \mathrm{x}])$.

(9) Realización africada (también llamada "asibilada" en aquel entonces)

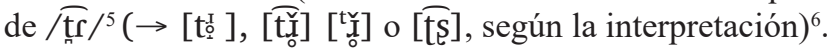

(10)Palatalización de las velares / k, g, x/ ( $\rightarrow[c, f \dot{j}$, ç]) ante /e, i/.

Hay razones de peso para pensar que los primeros dos fenómenos efectivamente no provienen del mapudungun. En el caso de la debucalización de la /s/ codal (1), el fonema/s/ es extremadamente poco frecuente en esta lengua, no parece ocurrir en posición codal excepto en un pequeño número de préstamos (e.g. asus 'ajo'), y no cuenta con el alófono [h]. Es decir, no existe en el mapudungun el fenómeno cuya presencia en el castellano de Chile Lenz le atribuye.

En cuanto a la realización fricativa o aproximante de /b, d, g/ (2), los fonemas labial y dental de la mayoría de las variedades de mapudungun no son /b/ y /d/, sino /f/ y / $/$ / (Sadowsky et al. 2013). En un número reducido de zonas, estos fonemas cuentan con alófonos sonoros $[\mathrm{v}, \beta]$ y [ð] (Salas 1976, Álvarez-Santullano 1986), mientras que en algunas variedades del norte del territorio mapuche actual, las variantes sonoras predominan hasta tal punto que cabe clasificarlas como fonemas $(/ \mathrm{v} / \mathrm{y}$ /ð/) (Salamanca 1997; Salamanca y Quintrileo 2009). En estas últimas localidades, [b] y [d] pueden existir como alófonos, pero son relativamente poco comunes. El fonema $/ \mathrm{\gamma} /$, por su parte, que es el que más se asemeja

\footnotetext{
5 En este tema seguimos a Sadowsky y Salamanca (2011), quienes clasifican el grupo $/ \mathrm{t} /+/ \mathrm{r} /$ como fonema en el castellano chileno, el cual se representa aquí como $/ \widetilde{\mathrm{tr}} /$.

6 Estas representaciones fonéticas siguen a Sadowsky y Salamanca (2011), quienes distinguen dos grados de fricación en ciertos fricativos y africados: corriente o neutra [ . ] e intensa o fortis [`]
} 
al /g/ del castellano, ocurre solo esporádicamente en la lengua mapuche. La escasez o inexistencia en el mapudungun de los fenómenos en cuestión lleva a concluir que su presencia en el castellano de Chile no se debe a la influencia de aquella lengua.

Aquí es necesario señalar que el argumento principal que esgrime Alonso en estos y varios otros casos se centra no en el mapudungun, del cual manifestaba un conocimiento apenas anecdótico, sino en el castellano. $\mathrm{Su}$ estrategia retórica típicamente consiste en buscar una localidad de habla hispana donde supuestamente se producía el mismo fenómeno cuya presencia en el castellano chileno Lenz atribuye al mapudungun. Luego, asevera enérgicamente que la única explicación posible es la evolución interna, es decir, el origen común a partir de un ancestro lingüístico común.

Ahora bien, la distribución de (1) y (2) es tan extensa a lo largo del mundo hispanoparlante que efectivamente resulta razonable concluir que son fenómenos de origen hispánico. Sin embargo, y como se verá en detalle en el caso de $\overparen{\mathrm{tr}} /(10)$, la explicación "internista", como la denominaremos, es convincente solo en los casos más extremos. En los demás, resulta ser implausible, o incluso improbable.

La velarización y vocalización de /d / ante / / / (3) no parecen contar con equivalencias en el mapudungun, y su distribución en el mundo hispánico fue relativamente extensa en etapas anteriores del castellano, lo cual argumenta a favor de una explicación internista. Sin embargo, Malvestitti (1993) menciona la velarización de /d/ como un rasgo propio del castellano de mapuches del sur de la Argentina, lo cual impide descartar por completo la posibilidad de que se haya producido su transferencia desde el mapudungun.

La conservación de $/ \Lambda /(4)$ representa un caso más ambiguo. La neutralización del contraste fonémico entre $/ K / \mathrm{y} / \mathrm{j} /$, con la consiguiente pérdida de $/ K /$ (fenómeno conocido como 'yeísmo'), está atestiguada en Chile desde comienzos del siglo XVIII (Contreras Seitz 2004: 183). Para inicios del siglo XX, la retención de $/ K /$ ya era excepcional, y se concentraba en la Provincia de Ñuble y la isla de Chiloé. Dado que estas localidades se hallan dentro del antiguo territorio mapuche (del subgrupo huilliche, en el caso de Chiloé), y que $/ K /$ esta plenamente vigente en este idioma, es plausible que su retención se deba a la influencia del mapudungun, tal como postuló Lenz. Sin embargo, la ausencia de $/ K /$ en las demás zonas del territorio mapuche requiere de una explicación, y la escasa información que existe sobre el fenómeno no lo permite. Por ende, lo único que se puede aseverar de manera fundada sobre (4) es que por el momento, no es posible descartar su posible origen mapuche.

La realización bilabial de /f/ (5) está presente en ciertas variedades de mapudungun en las cuales $[f]$ y $[\phi]$ están en variación libre, pero al parecer 
no existen estudios sobre la presencia de este fenómeno en el castellano de Chile. Lo mismo sucede con la realización lámino-alveolar de /t, d, s/ después de /r/ (6), la cual, además, parece no haberse investigado tampoco en el mapudungun. La ausencia de evidencia empírica en estos casos hace imposible emitir un juicio fundado sobre el origen de (5) y (6).

En el caso del empleo del fonema / $\overparen{\mathrm{t} \int} /$ en hipocorísticos y palabras del ámbito familiar (7), si bien su frecuencia podría ser mayor en Chile que en otros países hispanoparlantes, también faltan estudios empíricos que avalen o refuten esta idea. Es particularmente lamentable que sea así en este caso, dado que el mapudungun reemplaza cinco fonemas distintos por los postalveolares [ [t] $]$ o [S] (ambos alófonos del fonema $/ \widehat{t}$ / en el español chileno) para expresar la afectividad (Catrileo 2010), lo cual constituiría una explicación muy plausible del fenómeno en caso de que efectivamente ocurra en el español chileno con una frecuencia más alta de lo esperable.

Respecto de la realización fricativa de $/ \mathrm{r} /(\rightarrow[\breve{\mathrm{I}}, \mathrm{I}]$ ) (8), Alonso asevera que el fonema rótico del mapudungun no es fricativo por naturaleza, sino que tan solo se vuelve así esporádicamente, con el fin de expresar afecto (Alonso 1940, 287), y que por ende no podría ser el origen del rótico chileno, porque-según el mismo autor-éste sería siempre fricativo. Esta aseveración está triplemente equivocada. Primero, porque el fenómeno mapuche al cual Alonso apela no existe: cuando se quiere expresar el afecto mediante el rótico, éste no se vuelve (más) fricativo, sino que se reemplaza por [S] o [j] (Catrileo 2010). Segundo, porque el rótico de parte importante de los geolectos mapuches es, efectivamente, fricativo: en la mayoría de ellos es el fricativo sonoro /z/ (Sadowsky et al. 2013 retrata una de estas variedades), y en un número menor de geolectos -aquéllos que se hablan en el extremo sur de Chile (Sadowsky et al. 2015) y en ciertas zonas de Argentina ${ }^{7}$ (Sadowsky y Heggarty 2017)- es el fricativo áfono /s/. Y tercero, porque el fonema / $\mathrm{r}$ / chileno sí cuenta con un alófono aproximante-el lámino-alveolar [x]- que corresponde al tercer fono rótico del mapudungun, el retroflejo aproximante $/ \mathrm{J}$. Por todo lo anterior, no existe nada en el mapudungun, ni tampoco en el castellano de Chile, que impida que el fonema rótico chileno provenga de la lengua mapuche.

En este caso Alonso también recurre, otra vez más, al argumento internista para negar el posible origen mapuche de (8), señalando nueve países del mundo hispanoparlante donde $[\mathfrak{x}]$ (o [̌̃]) se utilizaría en por lo menos una localidad. Aquí es necesario reparar en uno de los errores fundamentales 
del argumento internista, el cual consiste en suponer que la presencia de un determinado rasgo en dos o más variedades lingüísticas significaría automática y obligatoriamente que todas las manifestaciones del rasgo comparten un mismo origen.

En términos evolutivos, lo que hacen los internistas es interpretar toda instancia de un rasgo compartido por distintas especies (variedades lingüísticas) como casos de homología, o descendencia de un ancestro común (en este caso, del castellano peninsular de la época de la colonización española de América). Sin embargo, existe otro mecanismo, tanto en la evolución biológica como en la lingüística, que puede producir el mismo resultado a partir de orígenes distintos: la evolución convergente. Este fenómeno, que los internistas ignoran u obvian, consiste en el desarrollo independiente de rasgos similares o idénticos en especies no relacionadas. Permite explicar, por ejemplo, la presencia de alas en los halcones, los murciélagos y las mariposas, pese a que no comparten un ancestro común. Del mismo modo, la evolución convergente puede explicar la presencia de un mismo fenómeno lingüístico (como, por ejemplo, la /r/ fricativa) en distintas variedades lingüísticas, sin necesidad de apelar a la descendencia de un ancestro lingüístico común. En estos casos, el mecanismo concreto de la convergencia es la transferencia lingüística desde una lengua hasta otra.

Quizás el caso más emblemático de la convergencia es el Sprachbund balcánico, un área lingüística del sur de la Europa oriental que está compuesta de lenguas de distintas familias, entre ellas el serbo-croata, el búlgaro y el macedonio (familia eslava); el rumano, el arrumano, el meglenorrumano y (en menor grado) el judeoespañol balcánico (familia itálica); el albanés (familia albanesa); el griego (familia helénica); el romaní balcánico (familia indoaria); y algunas variedades del turco (familia túrquica) (Tomić 2008: 184). Pese a que el ancestro común de estas lenguas debe de haber existido hace decenas de miles de años, cada una de ellas manifiesta un número importante de "fenómenos balcánicos". Éstos incluyen los artículos enclíticos y pospuestos, la reduplicación de objetos, el empleo de preposiciones en vez de casos gramaticales, la fusión de los casos dativo y genitivo, la fusión de la ubicación y la dirección, clíticos dativos en la frase nominal, un marcador del caso vocativo, la pérdida del infinitivo y su reemplazo por el subjuntivo, la comparación analítica de adjetivos y adverbios, y la evidencialidad (Tomić 2008: 188).

Dado que los fenómenos balcánicos rara vez están presentes en las otras lenguas de estas familias lingüísticas, su presencia en aquéllas que pertenecen al Sprachbund no puede deberse a la evolución interna a partir de un ancestro común. Y, de hecho, el consenso al respecto es que el mecanismo que produjo 
los fenómenos balcánicos fue "una situación de contacto que dio origen a la convergencia que se puede observar en esta área" (Lindstedt 2000: 231).

Este mismo mecanismo es el que se utiliza para explicar incontables casos de rasgos compartidos entre lenguas no emparentadas a lo largo del mundo, y es también el que propone Lenz para explicar los rasgos aparentemente mapuches en el castellano chileno.

Volviendo al caso específico de (8), es efectivamente probable que en algunos de los lugares que señala Alonso, la realización fricativa de $/ \mathrm{r} /$ tenga su génesis en un ancestro lingüístico común que desarrolló este alófono, y cuyos hablantes posteriormente se asentaron en algunas de las localidades que señala. A la vez, es probable que, en otras de estas zonas, el mismo rasgo haya surgido a raíz del contacto con una lengua indígena. Tanto en Ecuador, Perú y Bolivia -donde muchas de las variedades de quechua y aimara que se hablan cuentan con el rótico fricativo /x/ (Heggarty 2017)como en Chile - donde no pocas variedades del mapudungun cuentan con los róticos fricativos que se detallaron arriba-, la presencia de un fono de estas características en las variedades locales del castellano muy probablemente se debe a la evolución convergente, mediante el contacto y la posterior transferencia.

Respecto de la realización africada de / principal argumento al que recurre Alonso cuando asevera que no provendría del mapudungun es que "el araucano [mapudungun] no tiene el grupo tr" (Alonso 1940: 288). Y, lógicamente, se entiende, algo que no existe en una lengua no puede influir en otra. Pero la afirmación de Alonso es sumamente engañosa: la lengua mapuche no tiene el grupo $\operatorname{tr}(/ \mathrm{t} /+/ \mathrm{r} /)$ porque su $t r$ se clasifica como fonema $(/ / \mathrm{t} /$ /), como Alonso indudablemente sabía. De hecho, el fonema $t r$ es mencionado en todas las gramáticas del mapudungun que conocemos, incluyendo aquéllas a las cuales Alonso tuvo acceso, como la de Febres (1765), que él mismo cita (Alonso y Lida 1940: 90, nota 2). Además, el fonema tr se da en incontables lexemas de la lengua mapuche, tales como trapi, witran, tralkan, wentru, tranga tranga y kütral, un hecho que el filólogo peninsular no puede haber desconocido. El empleo de un argumento de esta calaña obliga a cuestionar la buena fe con que Alonso obró en este debate.

La existencia del fonema $/ \mathrm{tS} /$ en el mapudungun es doblemente importante, porque lo que se analiza como el grupo consonántico $/ \mathrm{t} /+/ \mathrm{r} /$ en otras variedades del castellano se comporta como fonema en el castellano chileno. Dicho fonema, que se representa aquí como $/ \mathrm{tr} /$, pero que igualmente bien podría definirse como / $/ \mathrm{r} /$, puede conmutarse

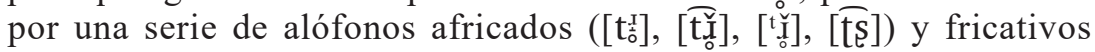

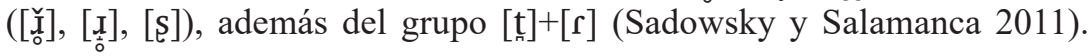


Nada de esto puede entenderse como producto de la simple "mecánica articulatoria", en palabras de Alonso (1940: 288). Cabe señalar, además, que uno de los alófonos del fonema $/ \mathrm{tr}_{\mathrm{r}} /$ del castellano chileno - $[\overline{\mathrm{ts}}]-$ es idéntico al principal alófono del fonema $/ \mathrm{ts} /$ del mapudungun, mientras que otro -[s]- existe en la lengua mapuche como alófono tanto de $\overleftarrow{\mathrm{ts}}^{8}$ como de $/ z /$ en posición final de palabra. Esta situación argumenta fuertemente a favor de la idea de que se transfirió desde el mapudungun hasta el castellano de Chile no solo un fenómeno fonético - una o más de las realizaciones africadas $\mathrm{y} / \mathrm{o}$ fricativas de $/ \mathrm{tr} /-$ sino todo un fonema, cambiando de este modo la estructura fonológica chilena. Una transferencia de esta naturaleza afecta la lengua a nivel sistémico, y sugiere que el contacto con el mapudungun tuvo aún más alcances de lo que se podría haber sospechado.

El otro argumento que Alonso esgrime aquí es, de nuevo, el internista, esta vez de manera implícita. Alega que "esa pronunciación [africada] del grupo tr tiene en nuestros dialectos la misma extensísima geografía que la rr asibilada [fricativa]" (1940: 288). Sin embargo, no cita ninguna investigación que avale esta aseveración, ni nombra los presumiblemente numerosísimos lugares que comprenderían dicha "extensísima geografía". No se pregunta si la $t r$ de la cual habla efectivamente existió en dichas localidades durante la época colonial, para que pudiera ser llevado a Chile, o si fue un desarrollo posterior que no tuvo posibilidad alguna de influir en el castellano del país. Tampoco se pregunta si un solo habitante de una de estas localidades efectivamente se asentó en Chile. En resumidas cuentas, el argumento de Alonso no es más que una aserción sin fundamentación alguna.

Existen dos argumentos adicionales en contra de la explicación internista de (9). Primero, el / tr̂. / chileno tiene no uno, sino toda una gama de alófonos (Figueroa 2008; Figueroa, Soto Barba y Nanculeo 2010; Sadowsky y Salamanca 2011; Sadowsky 2015); estos últimos estudios identifican nada menos que nueve. Sin embargo, aparte del grupo patrimonial [ [trc], Alonso

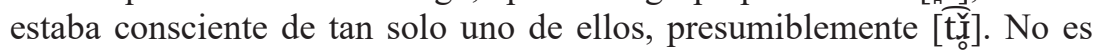
imposible que uno de estos alófonos sea efectivamente el mismo que el filólogo atribuye a otras zonas dialectales del castellano, y que la homología pueda explicar su presencia en Chile (aunque no se debe perder de vista que tampoco existen evidencias que avalen la idea). A la vez, es altamente improbable que este mecanismo haya operado los otros siete alófonos no patrimoniales, sobre todo cuando varios de ellos están presentes también en

\footnotetext{
$8 \quad$ Ver, por ejemplo, la pronunciación de motrin, trufken y trekan de la hablante de Aleucapi en $<$ https://soundcomparisons.com/\#/sl/es/Mapudungun/XO>.
} 
el mapudungun, y otros más comparten el mismo modo de articulación y tipo de sonoridad que los alófonos mapuches, diferenciándose solo por tener un punto de articulación levemente distinto. En estos casos, la transferencia desde el mapudungun constituye la explicación más coherente.

Y segundo, si bien pueden existir realizaciones africadas de $/ \mathrm{t} / \mathrm{t} / \mathrm{f} /$ en otros geolectos del castellano, hasta donde tenemos noticia, la africada retrofleja -que está presente tanto en el mapudungun como en el castellano de Chile- se ha detectado en escasas o nulas otras variedades de la lengua. Incluso en el valle central de Costa Rica, donde se ha reportado la existencia de tres róticas retroflejas ([^], [Z] y [r]), éstas no se manifiestan en los grupos consonánticos (como por ejemplo / $/ \mathrm{n} /+/ \mathbf{r} /)($ Calvo Shadid y Portilla Chaves 1998).

Por todo lo anterior, es altamente probable que el grupo consonántico patrimonial $/ \mathrm{t} /+/ \mathrm{f} /$ haya sido reemplazado en el castellano de Chile por el lámino-alveolar africado áfono $\widetilde{\mathrm{tr}} / \mathrm{h} /$, mediante la transferencia desde el mapudungun del fonema retroflejo africado áfono $/ \mathrm{ts}_{\mathrm{S}} /$, y que varios de sus alófonos también tengan su origen en el mapudungun,

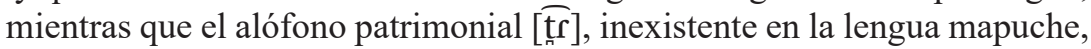
proviene con toda seguridad del castellano.

Finalmente, la palatalización de las velares $/ \mathrm{k}, \mathrm{g}, \mathrm{x} /$ ante /e, i/ que se produce en el castellano de Chile (10) no se asemeja a ningún otro proceso de palatalización conocido en el mundo hispanoparlante, al contrario de lo que dice Alonso. En el caso de /x/ ante [e, i], por ejemplo, el alófono palatalizado chileno es notoriamente más agudo -8 semitonos, o dos tercios de una octava-que su equivalente peninsular (Tapia y Valdivieso 1997). A la vez, la palatalización los fonemas velares $/ \mathrm{k} / \mathrm{y} / \mathrm{\gamma} /$ se manifiesta en el mapudungun hablado tanto en Chile como en Argentina (Sadowsky y Heggarty 2017), mientras que este proceso no se ha reportado en el castellano argentino. A la luz de estos hechos, es muy plausible que la palatalización de los velares (10) haya sido transmitido desde el mapudungun hasta el castellano de Chile.

En resumen, dos de los fenómenos que Lenz postula como provenientes del mapudungun no pueden haberse originado en esta lengua (1 y 2 ), y uno más (3) probablemente no surgió de ella, aunque la posibilidad no puede descartarse por completo. Cuatro de los fenómenos (4-7) no pueden ser evaluados rigurosamente en base a las evidencias que existen en la actualidad,

\footnotetext{
$9 \quad$ Nótese que este fenómeno, de muy larga data en Chile, ha ido retrocediendo a favor de $/ \mathrm{tr} /$ en los chilenos nacidos después de 1990, aproximadamente (Sadowsky 2015). Sin embargo, la motivación de este cambio es sociolingüística; no tiene relación con el contacto de lenguas.
} 
y requerirán de mayor estudio antes de pronunciarse al respecto. A la vez, tres de los fenómenos (8-10) probablemente provienen del mapudungun.

Esta situación dista mucho de la idea de la derrota aplastante de la tesis indigenista que se ha pregonado en el hispanismo durante tres cuartos de siglo. Sugiere, por el contrario, que el contacto lingüístico con el mapudungun puede haber influido en el castellano más de lo que tradicionalmente se cree, no solo en los fenómenos que mencionó Lenz, sino también en otros que hasta el momento no se han estudiado.

A continuación, se presentan los resultados de una investigación que indaga en un fenómeno de esta índole: la configuración fonética del sistema vocálico del castellano chileno. Se examina este sistema desde dos perspectivas: el timbre o calidad de las vocales individuales, y el tamaño del espacio acústico utilizado por el sistema en su conjunto. Se compara el sistema vocálico chileno con los sistemas de una serie de otras variedades del castellano y con el del mapudungun. Los resultados sugieren que las vocales chilenas se refonetizaron bajo la influencia del mapudungun.

\section{METODOLOGÍA}

Las vocales del castellano de Chile que se analizaron provienen de una muestra de 61 hablantes monolingües (30 mujeres, 31 hombres) de la Provincia de Concepción, ubicada en el centro-sur del país. Al momento de ser grabados, todos tenían entre 16 y 19 años de edad. Con el fin de alcanzar un alto grado de representatividad socioeconómica, se utilizó la metodología EMIS (Sadowsky, en prensa) para estratificar a los hablantes en cinco grupos socioeconómicos ( $\mathrm{A}, \mathrm{B}, \mathrm{Ca}, \mathrm{Cb}$ y $\mathrm{D} / \mathrm{E}$, desde el más alto hasta el más bajo), y se estableció una cuota de por lo menos nueve hablantes por grupo. De este modo, se logró incluir en la muestra a personas cuyo ingreso familiar mensual fluctuaba entre aproximadamente USD 180 y más de USD 3.300, y cuyos padres o apoderados contaban con un nivel educacional que iba desde la enseñanza primaria incompleta hasta el postgrado terminado.

La elicitación se realizó mediante la lectura de frases significativas y textos. Si bien esta técnica es poco utilizada a lo largo del mundo para estudiar las vocales (se suele preferir el habla más natural que se obtiene a través de la entrevista sociolingüística), se empleó en la presente investigación con el fin de maximizar la comparabilidad con los demás estudios de las vocales del castellano, los cuales usan este método casi sin excepción. 
Utilizando el programa Praat (Boersma y Weenink 2016), se seleccionaron 2301 vocales tónicas monoptongas ubicadas en entornos fonológicos compuestos exclusivamente de $/ \mathrm{p} \mathrm{t} \mathrm{k} \mathrm{b} \mathrm{d} \mathrm{g} \mathrm{f} \mathrm{f} \mathrm{s} \mathrm{x/,} \mathrm{inicio} \mathrm{de} \mathrm{enunciado}$ o fin de enunciado, y que se hallaban dentro de palabras polisilábicas. Se excluyeron las vocales áfonas (e.g. /'ka.sa/ $\rightarrow$ ['ka.sa]), las laringealizadas (producidas con voz creaky o chirriante), aquéllas que se produjeron mientras el hablante se reía, bostezaba o tosía, y las que se emitieron cuando había un nivel perceptible de ruido de fondo. También se excluyeron las vocales /i/ y /e/ después de / $\mathrm{x} /$, para así evitar los posibles efectos de la fuerte palatalización que esta consonante experimenta al encontrarse en contacto con las vocales anteriores. El análisis contempló los $30 \mathrm{~ms}$ centrales del estado estable de cada vocal.

Para determinar el timbre de las vocales, se midieron los valores en hertz de los primeros dos formantes (F1 y F2) de cada token mediante un script de Praat, y luego se calculó el valor promedio de las mediciones correspondientes al lapso analizado. Con el fin de disponer de un punto de referencia invariable para la comparación de las vocales de las distintas variedades lingüísticas, todas las cartas formánticas que se presentan incluyen un conjunto de vocales de referencia basadas en la propuesta de Lindblom (1986), con muchas de las modificaciones sugeridas por Iivonen (1994).

Para determinar el tamaño del espacio acústico de los diversos sistemas vocálicos, se empleó el paquete vowels.R (Kendall y Thomas 2014) para el lenguaje de programación R ( R Core Team 2016) para convertir los valores de F1 y F2 en ERB, una unidad psicoacústica que aproxima la naturaleza esencialmente logarítmica de la percepción auditiva humana. Luego, se utilizó un script de $\mathrm{R}$ que genera polígonos formados por los valores medianos en ERB de los primeros dos formantes de /i/, /e/, /a/, /o/, /u/, /ì/ (en el caso del mapudungun), e /i/ de nuevo para cerrar el polígono. Posteriormente, se calculó el área del polígono resultante en $\mathrm{ERB}^{2}$ con el mismo script. En la Figura 1 se presenta un ejemplo gráfico del resultado de este proceso. 


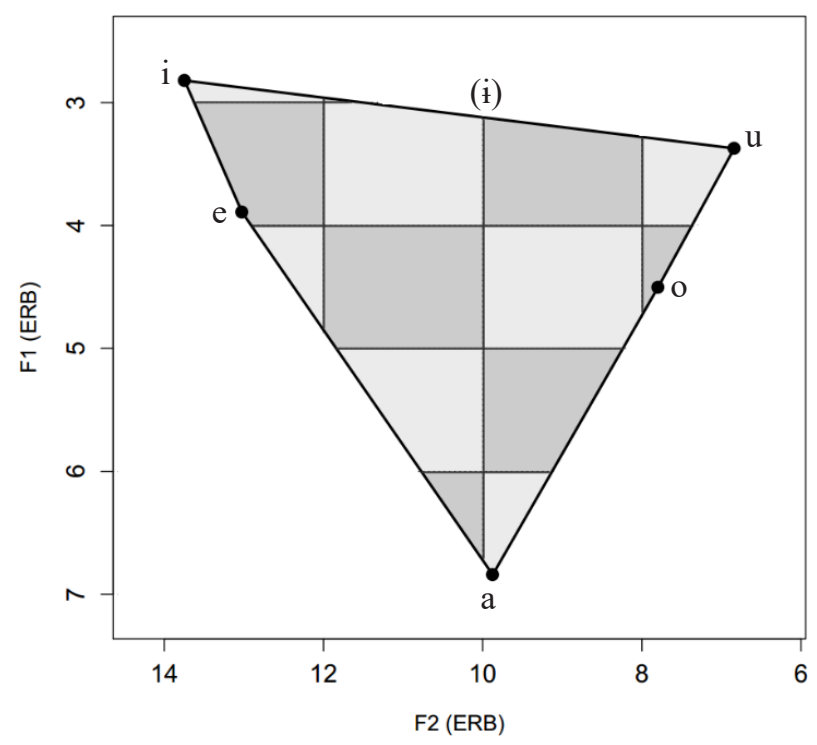

Figura 1. Ejemplo de un polígono utilizado para calcular el área del espacio acústico empleado por un sistema vocálico hipotético, en ERB².

\section{RESULTADOS}

En la Tabla 1 se presentan los valores promedios de F1 y F2 de las vocales tónicas de los 61 hablantes del castellano chileno que participaron en el presente estudio.

\begin{tabular}{lccc}
\hline Sexo & Vocal & F1 (Hz) & F2 (Hz) \\
\hline Femenino & i & 401 & 2595 \\
& e & 504 & 2026 \\
& a & 807 & 1655 \\
& o & 575 & 1317 \\
& u & 439 & 1199 \\
\hline
\end{tabular}




\begin{tabular}{llll}
\hline Masculino & i & 350 & 2073 \\
& e & 428 & 1718 \\
& a & 593 & 1448 \\
& o & 477 & 1166 \\
u & 378 & 1086 \\
\hline
\end{tabular}

Tabla 1. Valores promedios, en Hz, de F1 y F2 de los hablantes de la presente investigación, según el sexo.

Estos valores forman la base de las comparaciones del timbre vocálico y del área del espacio acústico que se presentan en 3.1 y 3.2.

\subsection{TIMBRE VOCÁLICO}

\subsubsection{Hablantes femeninas}

En el presente apartado, se compara el timbre de las vocales de las hablantes femeninas del castellano de Chile con el de las hablantes femeninas del castellano de Argentina (Aronson et al. 2000), España (Chládková, Escudero, y Boersma 2011; Martínez Celdrán 1995) y Perú (Chládková, Escudero y Boersma 2011) (Figura 2 a Figura 5, respectivamente), y con el de mujeres hablantes del mapudungun (Sadowsky et al. 2013) (Figura 6).

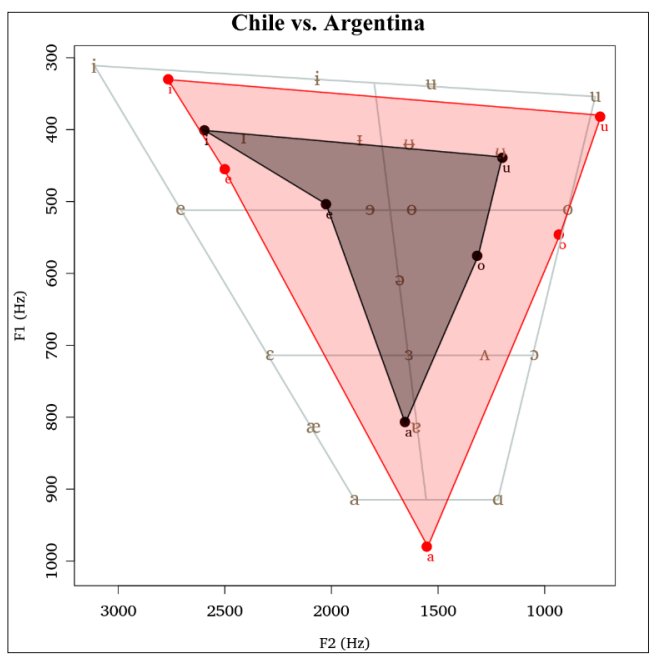

Figura 2. Vocales de hablantes femeninas del castellano chileno (presente investigación, en negro) y argentino (Aronson et al. 2000, en rojo). 


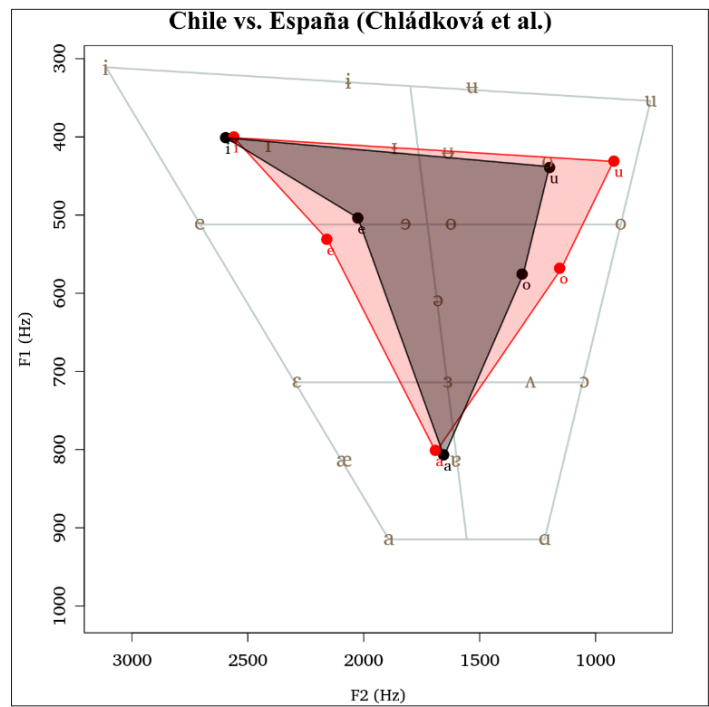

Figura 3. Vocales de hablantes femeninas del castellano chileno (presente investigación, en negro) y peninsular (Chládková, Escudero y Boersma 2011, en rojo).

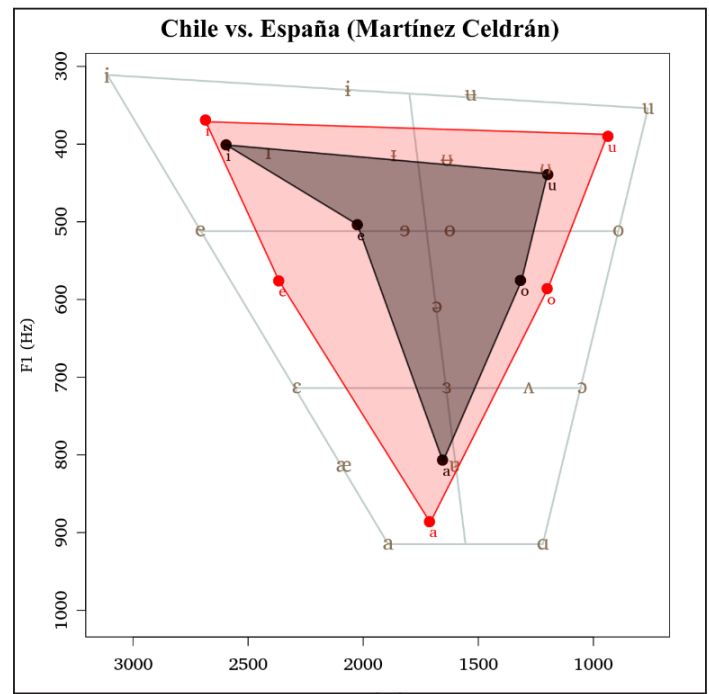

Figura 4. Vocales de hablantes femeninas del castellano chileno (presente investigación, en negro) y peninsular (Martínez Celdrán 1995, en rojo). 


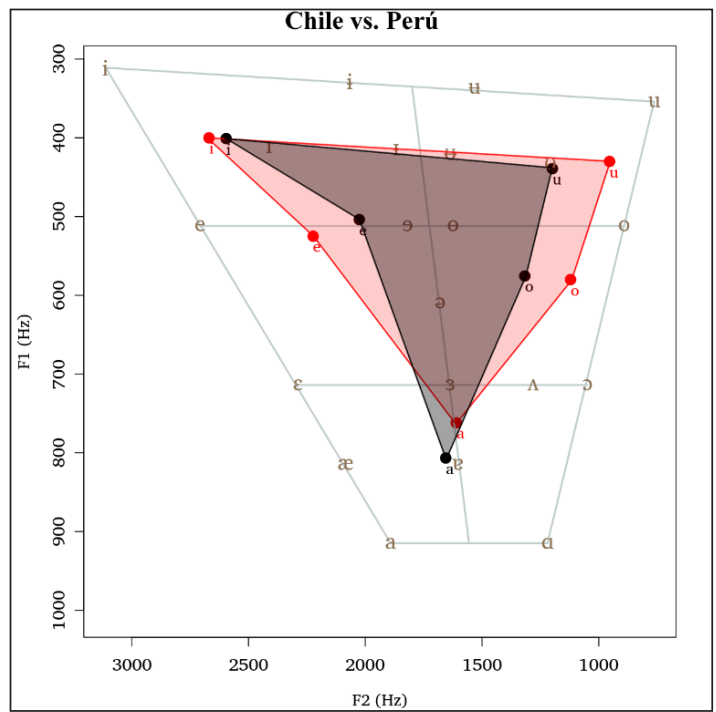

Figura 5. Vocales de hablantes femeninas del castellano chileno (presente investigación, en negro) y peruano (Chládková, Escudero, y Boersma 2011, en rojo).

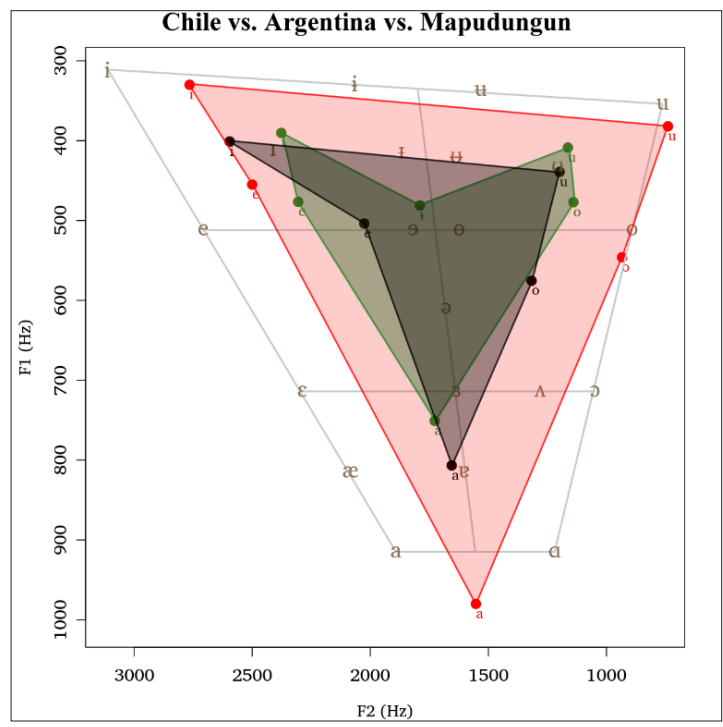

Figura 6. Vocales de hablantes femeninas del castellano chileno (presente investigación, en negro), del mapudungun (Sadowsky et al. 2013, en verde) y del castellano argentino (Aronson et al. 2000, en rojo). 
Si bien existe un nivel no menor de variación entre las vocales de los otros geolectos del castellano, las vocales chilenas son casi siempre las más medio-centrales. Las únicas excepciones las constituyen la/i/y la /a/ de las mujeres peninsulares según Chládková, Escudero y Boersma (2011), (Figura 3) (pero no según el estudio del mismo dialecto realizado por Martínez Celdrán (1995), (Figura 4)), y la /a/ de las mujeres peruanas (Figura 5). En los otros 17 casos, se mantiene el patrón de mayor medio-centralización de las vocales chilenas.

El sistema vocálico de las hablantes femeninas de mapudungun, por su parte, traslapa en buena medida las vocales de las hablantes del castellano chileno, como se puede apreciar en la Figura 6. Existe variación en las vocales medias /e/ y /o/, pero en general, y especialmente en el caso de los tres puntos extremos del sistema $-/ \mathbf{i} / / \mathbf{a} / \mathrm{y} / \mathbf{u} /-$, el sistema vocálico del mapudungun es el que más se asemeja al del castellano de Chile.

\subsubsection{Hablantes masculinos}

A continuación, se compara el timbre vocálico de los hablantes masculinos del castellano de Chile con el de los hablantes masculinos del castellano de Argentina (Aronson et al. 2000; Godínez 1978) (Figura 7 y Figura 8), Ecuador (Guion 2003) (Figura 9), España (Chládková, Escudero y Boersma 2011; Godínez 1978; Martínez Celdrán 1995; Morimoto 1988; Quilis y Esgueva 1983) (Figura 10 a Figura 14), México (Godínez 1978) (Figura 15) y Perú (Chládková, Escudero, y Boersma 2011) (Figura 16), y con el de los hablantes masculinos del mapudungun (Sadowsky et al. 2013) (Figura 17).

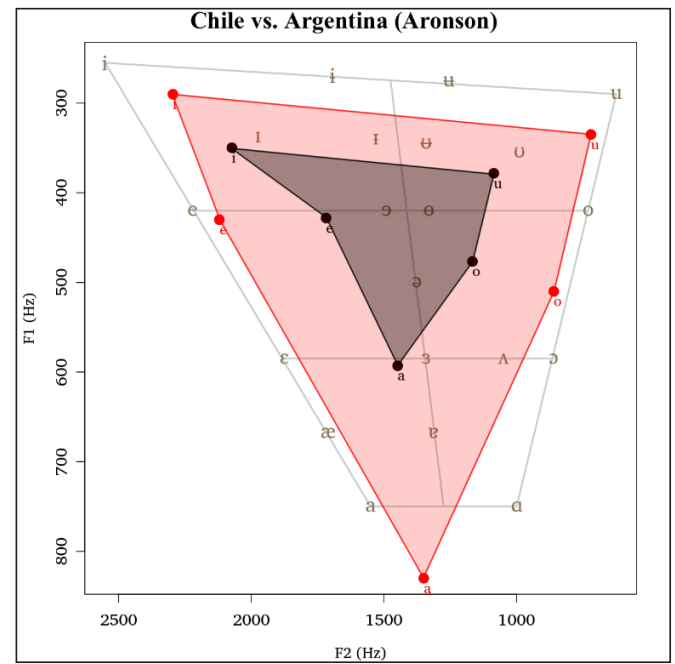

Figura 7. Vocales de hablantes masculinos del castellano chileno (presente investigación, en negro) y argentino (Aronson et al. 2000, en rojo). 


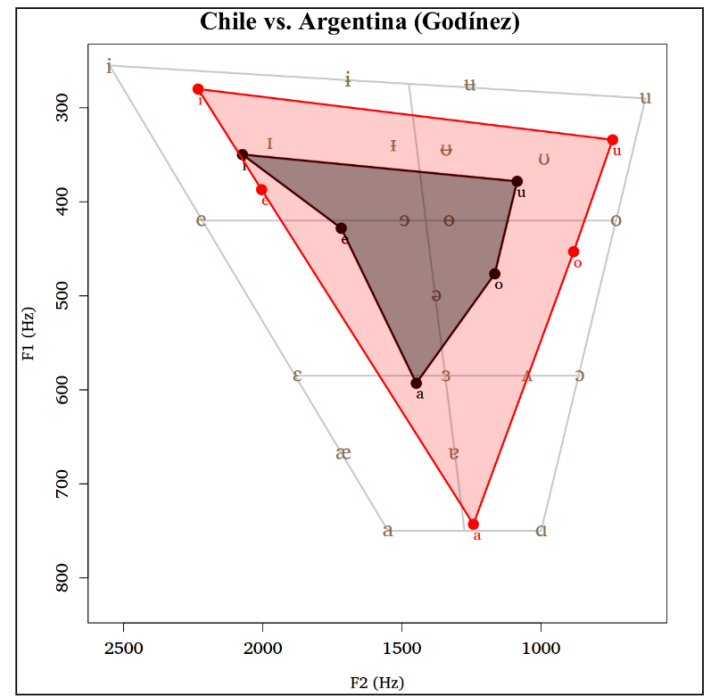

Figura 8. Vocales de hablantes masculinos del castellano chileno (presente investigación, en negro) y argentino (Godínez 1978, en rojo).

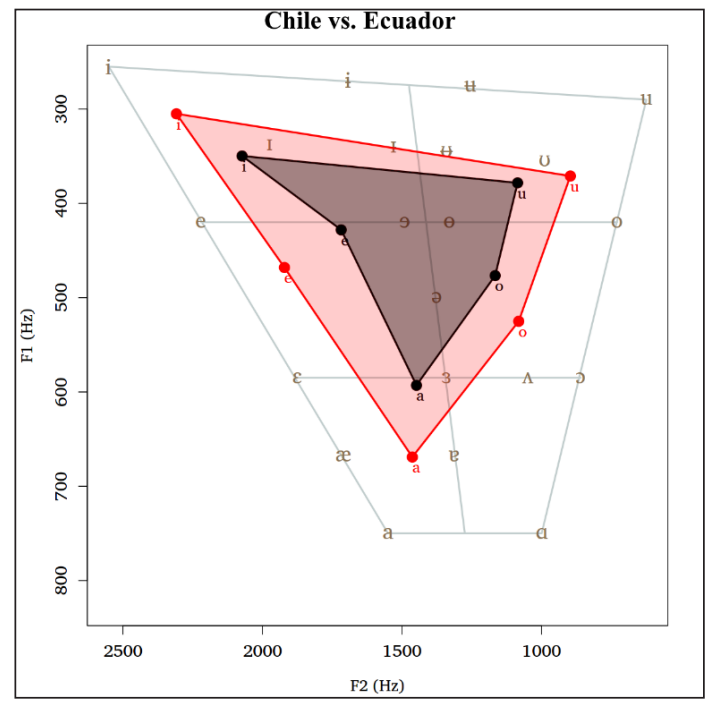

Figura 9. Vocales de hablantes masculinos del castellano chileno (presente investigación, en negro) y ecuatoriano (Guion 2003, en rojo). 


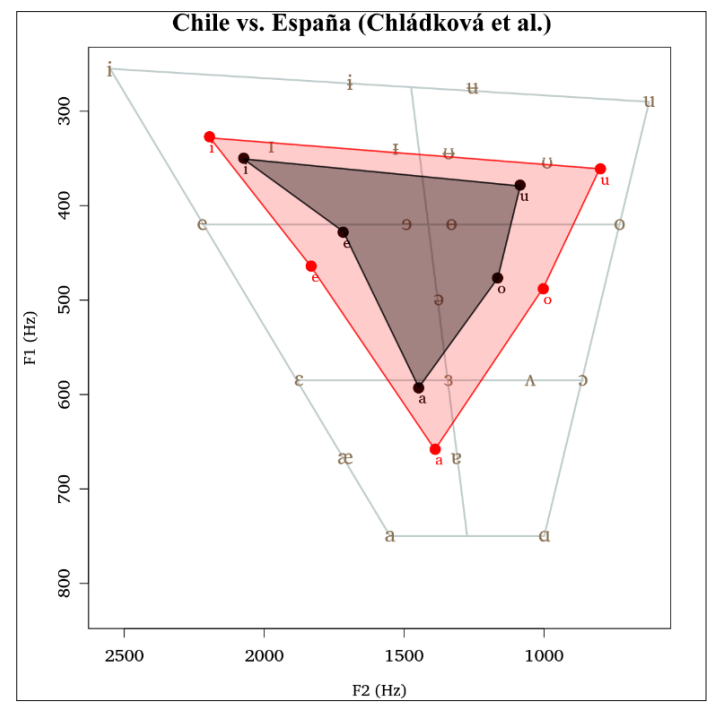

Figura 10. Vocales de hablantes masculinos del castellano chileno (presente investigación, en negro) y peninsular (Chládková, Escudero, y Boersma 2011, en rojo).

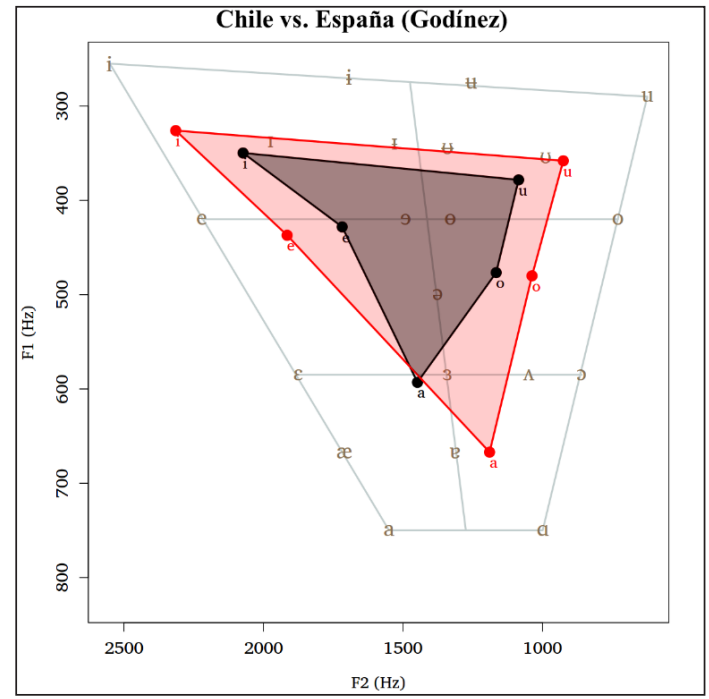

Figura 11. Vocales de hablantes masculinos del castellano chileno (presente investigación, en negro) y peninsular (Godínez 1978, en rojo). 


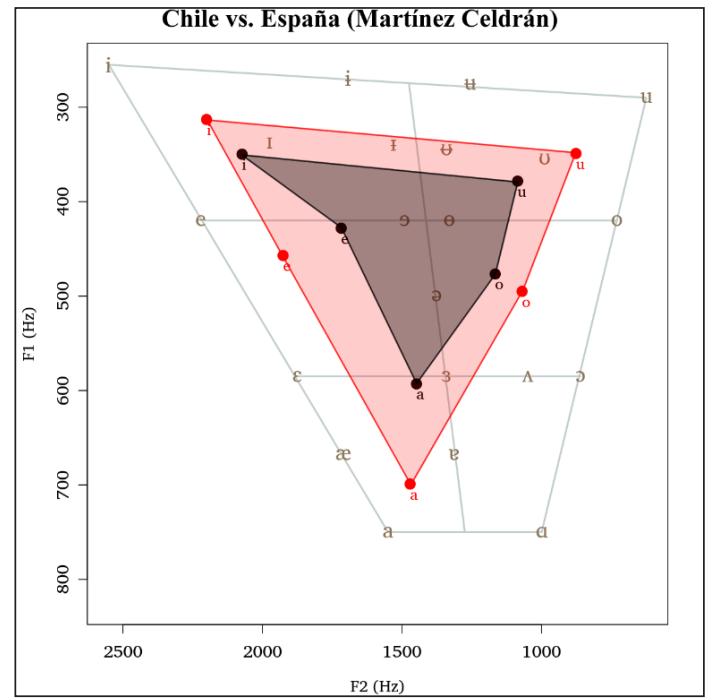

Figura 12. Vocales de hablantes masculinos del castellano chileno (presente investigación, en negro) y peninsular (Martínez Celdrán 1995, en rojo).

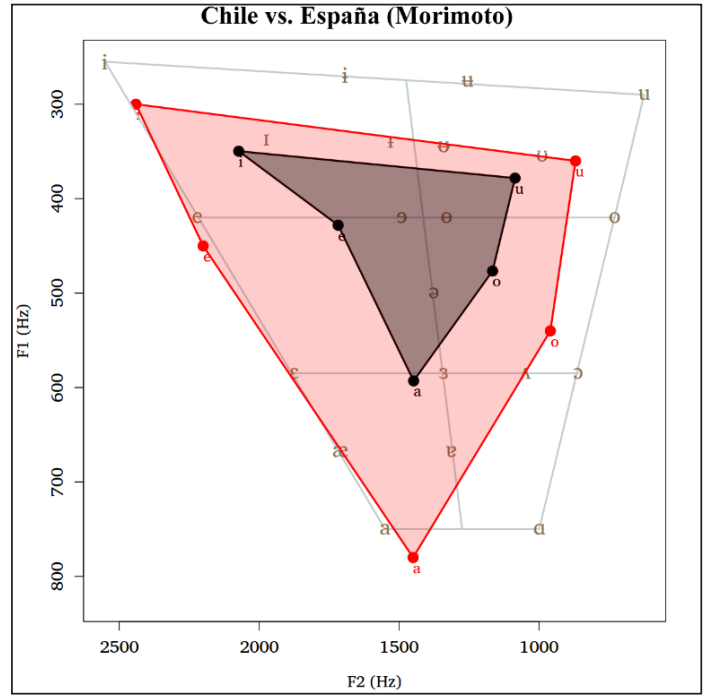

Figura 13. Vocales de hablantes masculinos del castellano chileno (presente investigación, en negro) y peninsular (Morimoto 1988, en rojo). 


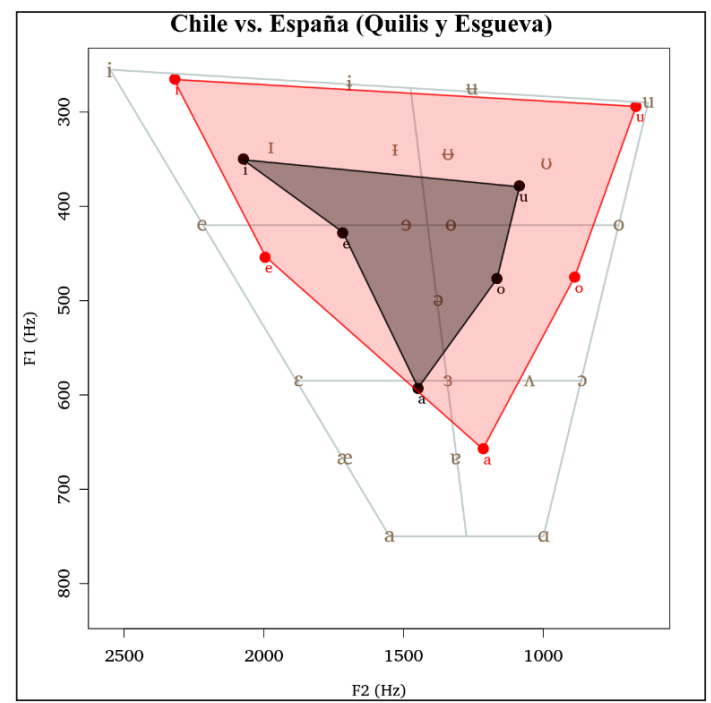

Figura 14. Vocales de hablantes masculinos del castellano chileno (presente investigación, en negro) y peninsular (Quilis y Esgueva 1983, en rojo).

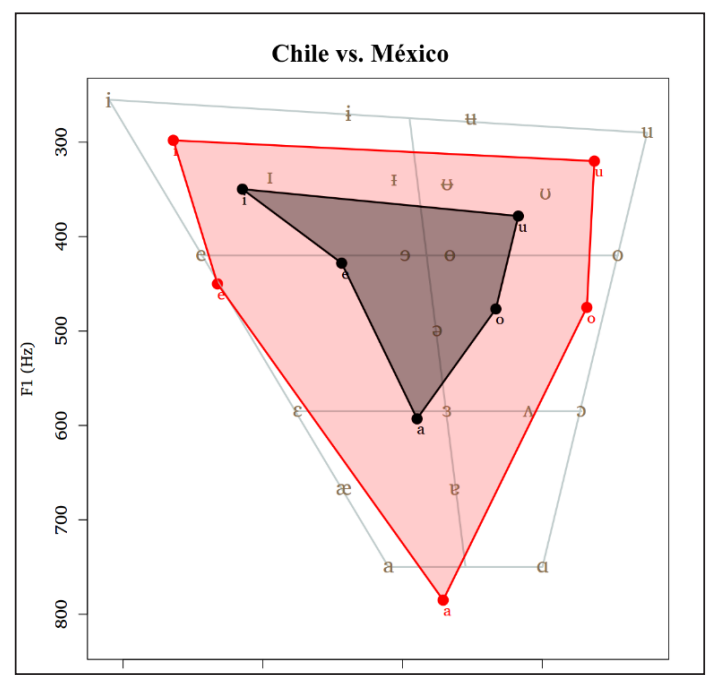

Figura 15. Vocales de hablantes masculinos del castellano chileno (presente investigación, en negro) y mexicano (Godínez 1978, en rojo). 


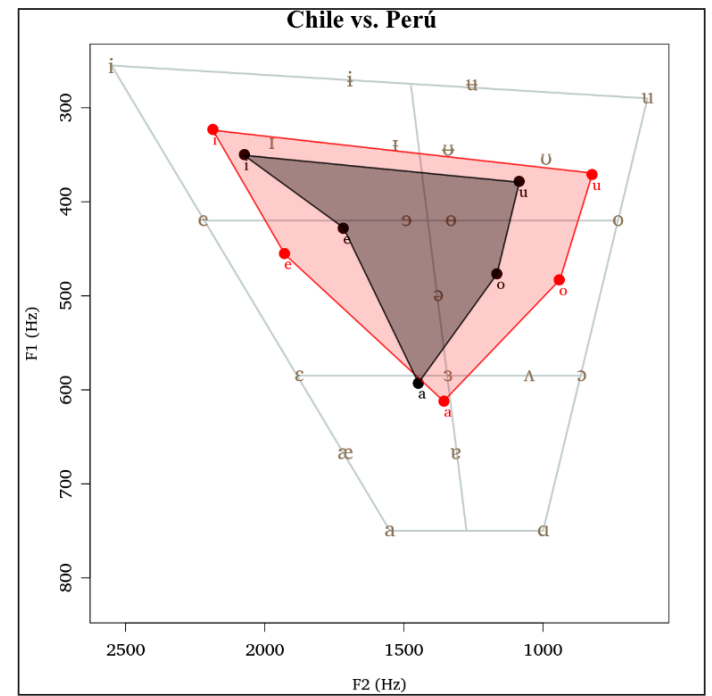

Figura 16. Vocales de hablantes masculinos del castellano chileno (presente investigación, en negro) y peruano (Chládková, Escudero, y Boersma 2011, en rojo).

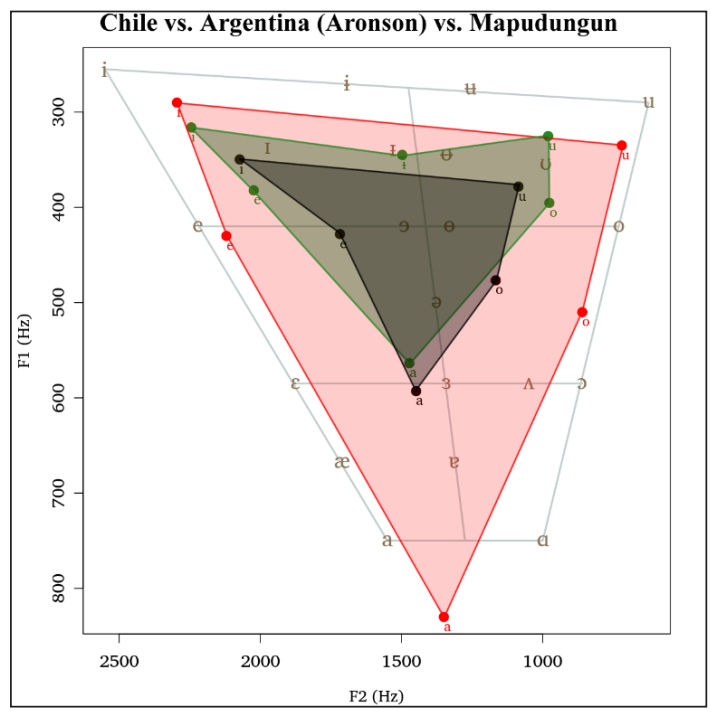

Figura 17. Vocales de hablantes masculinos del castellano chileno (presente investigación, en negro), del mapudungun (Sadowsky et al. 2013, en verde) y del castellano argentino (Aronson et al. 2000, en rojo). 
En el caso de los hombres, se manifiesta el mismo patrón que se observa en las mujeres, pero de manera más extrema. Primero, las vocales chilenas son notablemente más medio-centrales que las de los demás geolectos de la lengua; de los 50 casos analizados aquí (cinco vocales de cada uno de 10 estudios), existe una sola excepción a este patrón, y es parcial: la /a/ peruana es levemente más central, pero a la vez levemente menos media, que la /a/ chilena (Figura 16). Segundo, el sistema vocálico del mapudungun es el que más se asemeja al del castellano de Chile, siendo también notablemente medio-central (Figura 17). Y tercero, la correspondencia entre estos últimos dos sistemas se concentra en las tres vocales extremas, $/ \mathbf{i} /, / \mathbf{a} / \mathrm{y} / \mathbf{u} /$.

\subsection{TAMAÑO DEL ESPACIO ACÚSTICO DE LOS SISTEMAS VOCÁLICOS}

\subsubsection{Hablantes femeninas}

En la Tabla 2 se presenta el tamaño, en ERB ${ }^{2}$, del espacio acústico utilizado por los sistemas vocálicos de las hablantes femeninas de las mismas variedades lingüísticas que se examinaron en el apartado 3.1.1. Se presenta también la diferencia, en términos porcentuales, entre el sistema vocálico chileno y los demás sistemas. Los valores en $\mathrm{ERB}^{2}$ se grafican en la Figura 18.

\begin{tabular}{lcc}
\hline Variedad y estudio & $\begin{array}{c}\text { Área } \\
\text { (ERB }^{2} \text { ) }\end{array}$ & $\begin{array}{c}\text { Diferencia con } \\
\text { cast. chileno (\%) }\end{array}$ \\
\hline Mapudungun (Sadowsky et al. 2013) & 11,96 & $-4,9$ \\
Chile (presente estudio) & 12,57 & - \\
España (Chládková, Escudero y Boersma 2011) & 19,14 & 52,3 \\
Perú (Chládková, Escudero y Boersma 2011) & 19,20 & 52,7 \\
España (Martínez Celdrán 1995) & 27,87 & 121,7 \\
Argentina (Aronson et al. 2000) & 39,26 & 212,3 \\
\hline
\end{tabular}

Tabla 2. Valores, en $\mathrm{ERB}^{2}$, del área del espacio acústico de las vocales de hablantes femeninas, y diferencia porcentual en comparación con el castellano de Chile. 


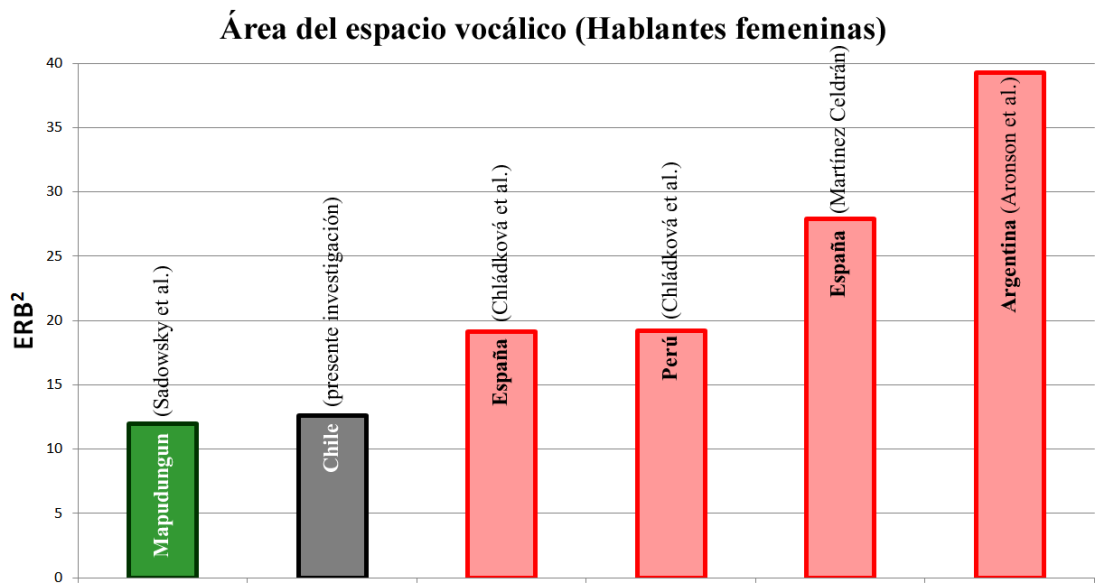

Figura 18. Tamaño, en $\mathrm{ERB}^{2}$, del espacio vocálico de hablantes femeninas del mapudungun, del castellano chileno, y de tres otras variedades de castellano según cuatro estudios distintos.

El tamaño del espacio acústico del sistema vocálico de las hablantes femeninas del mapudungun es casi idéntico al de las hablantes del castellano chileno: 11,96 $\mathrm{ERB}^{2}$ y 12,57 $\mathrm{ERB}^{2}$, respectivamente. La variedad de castellano más cercano al chileno, el de España según Chládková, Escudero y Boersma (2011), utiliza 19,14 ERB ${ }^{2}$, lo cual equivale a un espacio que es 52,3\% mayor. La diferencia más grande se produce en el castellano de Argentina, cuyo espacio vocálico ocupa $39,26 \mathrm{ERB}^{2}$, lo cual es $212,3 \%$ mayor que el sistema de las mujeres chilenas.

\subsubsection{Hablantes masculinos}

En la Tabla 3 se da a conocer el tamaño, en $\mathrm{ERB}^{2}$, del espacio acústico utilizado por los sistemas vocálicos de los hablantes masculinos de las mismas variedades lingüísticas que se examinaron en el apartado 3.1.2. Se presenta también la diferencia, en términos porcentuales, que existe entre el sistema chileno y los demás sistemas. Los valores en $\mathrm{ERB}^{2}$ se grafican en la Figura 19. 


\begin{tabular}{lcc}
\hline Variedad y estudio & $\begin{array}{c}\text { Área } \\
\text { (ERB }^{2} \text { ) }\end{array}$ & $\begin{array}{c}\text { Diferencia con } \\
\text { cast. chileno (\%) }\end{array}$ \\
\hline Chile (presente estudio) & 8,11 & - \\
Mapudungun (Sadowsky et al. 2013) & 12,50 & 54,1 \\
España (Godínez 1978) & 16,53 & 103,8 \\
Perú (Chládková, Escudero y Boersma 2011) & 17,52 & 116,0 \\
España (Chládková, Escudero y Boersma 2011) & 18,13 & 123,6 \\
Ecuador (Guion 2003) & 19,16 & 136,3 \\
España (Martínez Celdrán 1995) & 19,70 & 142,9 \\
Argentina (Godínez 1978) & 26,43 & 225,9 \\
España (Morimoto 1988) & 29,00 & 257,6 \\
España (Quilis y Esgueva 1983) & 31,51 & 288,5 \\
México (Godínez 1978) & 32,75 & 303,8 \\
Argentina (Aronson et al. 2000) & 34,52 & 325,6 \\
\hline
\end{tabular}

Tabla 3. Valores, en $\mathrm{ERB}^{2}$, del área del espacio acústico de las vocales de hablantes masculinos, y diferencia porcentual en comparación con el castellano de Chile.

Área del espacio vocálico (Hablantes masculinos)

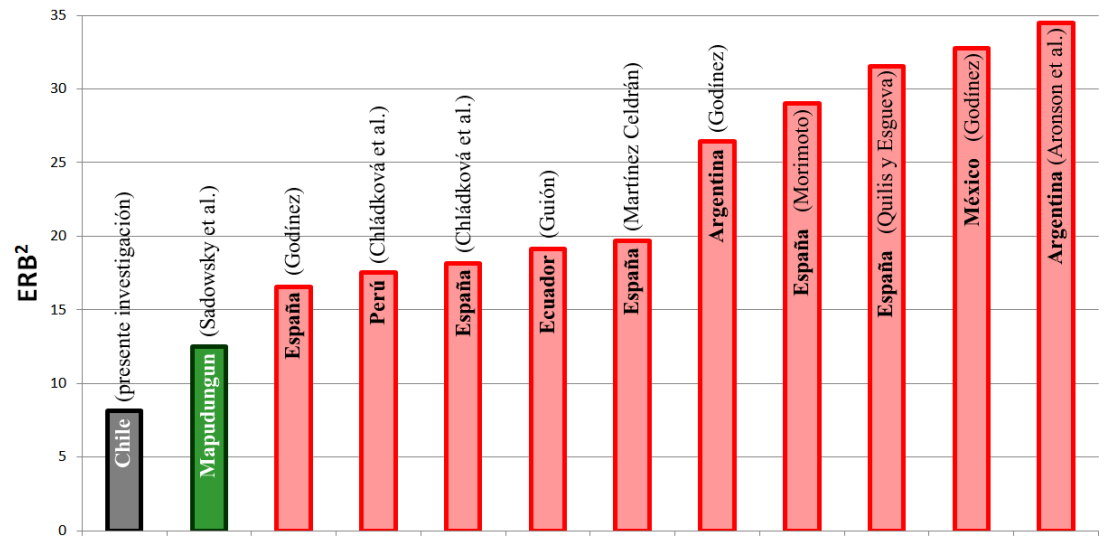

Figura 19. Tamaño, en $\mathrm{ERB}^{2}$, del espacio vocálico de hablantes masculinos del castellano chileno, del mapudungun y de cinco otras variedades del castellano según 10 estudios diferentes. 
En el caso de los hablantes masculinos, el castellano de Chile utiliza aún menos espacio acústico $\left(8,11 \mathrm{ERB}^{2}\right)$ que el mapudungun $\left(12,50 \mathrm{ERB}^{2}\right)$, que es la variedad lingüística que más se le asemeja. El geolecto del castellano más parecido al chileno es el de España según Godínez (1978), que emplea $16,53 \mathrm{ERB}^{2}$, lo que representa un $103,8 \%$ más espacio que el sistema chileno. Al otro extremo, se encuentra el castellano argentino según Aronson et al. (2000), el cual utiliza $34,52 \mathrm{ERB}^{2}$, lo cual es $325,6 \%$ mayor que el sistema vocálico de los hombres chilenos.

\section{DISCUSIÓN}

\subsection{UN SISTEMA VOCÁLICO ANÓMALO EN EL MUNDO HISPÁNICO}

Fonológicamente, el sistema vocálico chileno es idéntico al de los demás geolectos de esta lengua: todos constan de cinco fonemas vocálicos, y no seis, como es el caso del mapudungun. Fonéticamente, en cambio, las vocales chilenas son profundamente diferentes de las de las otras variedades del castellano, a la vez que son muy similares a las vocales del mapudungun.

Tal como se mostró en el apartado 3, las vocales del castellano de Chile son más medio-centrales que las de todas las demás variedades de la lengua que se examinaron, las cuales comprenden cinco países (Argentina, Ecuador, España, México y Perú) y 14 estudios distintos. De los 70 casos de vocales que se analizaron, este patrón se manifiesta plenamente en 66 de ellos, y parcialmente en uno más.

Por otra parte, se mostró que el sistema vocálico chileno utiliza un espacio acústico marcadamente menor que los otros geolectos de la lengua. En las hablantes femeninas, el espacio empleado por las otras variedades de castellano es, en promedio, 109,8\% mayor que el de la variedad chilena, mientras que en los hablantes masculinos este valor asciende a 202,4\%. El espacio utilizado por el sistema vocálico del mapudungun, en cambio, es solo $4,9 \%$ menor que el del castellano de Chile en el caso de las mujeres, y solo $54,1 \%$ mayor en el caso de los hombres.

En resumen, de todas las variedades lingüísticas estudiadas, las vocales del mapudungun son las que más se asemejan a las vocales del castellano de Chile según ambas métricas utilizadas. 


\subsection{LA IMPROBABILIDAD DE LA RETENCIÓN}

El hecho de que todos los sistemas vocálicos del castellano que se han examinado excepto el chileno sean fundamentalmente periféricos, por una parte, y que utilicen un espacio acústico mucho mayor que el chileno, por otra, indica que la actual configuración de las vocales chilenas no puede explicarse como el producto de la retención de un sistema vocálico de un estadio anterior del castellano. De lo contrario, se observarían sistemas similares al chileno en distintos dialectos de la lengua, lo cual no es el caso.

Por otra parte, aunque existieran tamañas variedades lingüísticas -una posibilidad que no se puede descartar, dada la relativa escasez de estudios de las vocales del castellano- su existencia solo avalaría la explicación internista si resultara posible demostrar (i) que los hablantes de estas variedades hipotéticas y los hablantes del castellano chileno comparten ancestros comunes (e.g. colonizadores provenientes de la misma localidad de España); (ii) que dichos ancestros se asentaron tanto en Chile como en las otras zonas en números suficientes para establecer o cambiar la pronunciación de la lengua en los lugares de destino; y (iii) que la variedad lingüística ancestral contaba con un sistema vocálico fuertemente medio-centralizado (su presencia en la actualidad de ninguna manera lo garantiza). De no cumplirse estas condiciones, la existencia de sistemas vocálicos similares al chileno en otros dialectos hispánicos constituiría, con toda probabilidad, un mero caso de evolución convergente.

\subsection{EL ORIGEN DE LA INNOVACIÓN}

Atribuir la gran similitud que existe entre las vocales del castellano de Chile y las del mapudungun a la mera coincidencia requeriría de no poca credulidad. La probabilidad de que hayan surgido espontáneamente, y por simple casualidad, sistemas vocálicos tan similares en dos lenguas que carecen de todo parentesco genético, pero que se hablan en un mismo territorio desde hace siglos, es de por sí extremadamente baja.

Esta probabilidad se reduce aún más cuando se considera el hecho de que ambos sistemas violan el principio de máxima dispersión (Liljencrants y Lindblom 1972; Crothers 1978; Lindblom 1986; Disner 1984), el cual señala que las vocales de las distintas lenguas del mundo tienen una fuerte tendencia de posicionarse de modo tal que las diferencias acústicas y articulatorias que existen entre ellas se maximicen. De las 100 lenguas con cinco vocales que Schwartz et al. (1997a, 1997b) examinaron, el $97 \%$ cuenta con las vocales 
periféricas /i/, /e/, /a/, /o/ y /u/. En cambio, las vocales del castellano de

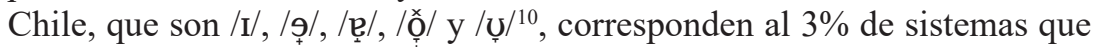
no sigue este patrón.

Según el mismo estudio, de las 54 lenguas con seis vocales que se examinaron, solo el $22 \%$ emplea una configuración similar a la del mapudungun, en la cual la sexta vocal se ubica entre la cerrada anterior y la cerrada posterior. Sin embargo, y al contrario de lo que sucede en los demás sistemas que tienen esta configuración, las vocales del mapudungun no son periféricas, sino medio-centrales: en vez de /i/, /e/, /a/, /o/, /u/ y /i /, son /I/, /ë/, /e /, /ö/, /৩/ y / / / (Sadowsky et al. 2013), la cual es una configuración tan poco común que Schwartz et al. no la detectaron ${ }^{11}$.

En resumen, tanto las vocales del castellano de Chile como las del mapudungun constituyen verdaderas aberraciones tipológicas. En consecuencia, la probabilidad de que estos dos sistemas vocálicos tan poco comunes en el mundo, y tan similares entre sí, hayan surgido por mera coincidencia en un mismo territorio y en lenguas que no cuenten con parentesco alguno entre sí, es prácticamente nula.

Por todo lo anterior, es forzoso concluir que uno de los dos sistemas vocálicos se desarrolló primero, y que posteriormente influyó en el otro, cambiando profundamente su naturaleza fonética. Dado que el sistema vocálico chileno no tiene precedentes conocidos en el mundo hispánico, y que es mínima la probabilidad de que su actual configuración haya surgido de un proceso espontáneo y sin influencias externas, es razonable concluir que fue el mapudungun que partió con un sistema vocálico fuertemente mediocentralizado, y que el castellano chileno se refonetizó bajo su influencia.

\subsection{El MECANISMO QUE GENERÓ EL CAMBIO}

\subsection{1. ¿Procesos sociolingüísticos?}

Existe una serie de mecanismos sociolingüísticos que generan cambios en las lenguas, y que en teoría podrían haber generado la refonetización del sistema

10 Los fonemas que se presentan aquí corresponden a los datos que arrojó la presente investigación. La tradición de utilizar las vocales cardinales para representar los fonemas vocálicos del castellano no hace más que ocultar la verdadera naturaleza de los distintos sistemas, y no puede justificarse en el presente contexto.

${ }_{11}$ Los fonemas vocálicos del castellano de Chile y del mapudungun que se presentan aquí corresponden a los valores promedios de las vocales de los hombres y las de las mujeres. 
vocálico del castellano de Chile bajo la influencia del mapudungun. Un primer mecanismo es la búsqueda del prestigio. En este caso, un determinado sector de la sociedad adopta ciertos rasgos lingüísticos que asocia con un grupo de mayor prestigio, con la esperanza -consciente o no- de que esta medida aumente su propio prestigio social.

Un segundo mecanismo es la fuga desde la estigmatización. En este caso, un grupo de bajo prestigio social es identificado, y posiblemente discriminado, a raíz de alguna característica de su habla. El cambio se produce cuando los hablantes afectados modifican o abandonan uno o más de los rasgos estigmatizados, para así dificultar o impedir su identificación como miembros del grupo en cuestión.

Un tercer mecanismo es el prestigio encubierto. En este caso, una determinada comunidad de habla adopta o mantiene rasgos lingüísticos que son menoscabados por otros sectores de la sociedad, por dos posibles razones: para expresar su rechazo de dichos sectores, o bien para fortalecer por oposición la identidad y solidaridad de su propia comunidad.

Ninguno de estos mecanismos puede explicar la refonetización del sistema vocálico del castellano de Chile. El pueblo mapuche siempre ha sido de bajo prestigio para los otros sectores de la sociedad chilena, por lo cual es inimaginable que su sistema vocálico haya sido imitado o adoptado conscientemente por el resto de la sociedad con el objetivo de aumentar su propio prestigio. Por otra parte, si hubiera operado la fuga desde la estigmatización, el sistema vocálico chileno habría mantenido su configuración original (presumiblemente periférica), o bien habría aumentado aún más su perifericidad, con el fin de maximizar la distancia perceptual entre su habla y la del grupo de bajo prestigio -los mapuches-, lo cual es precisamente lo contrario de lo que sucedió en los hechos. Finalmente, el prestigio encubierto tampoco ofrece una explicación plausible, ya que opera solo en subgrupos de la sociedad, en contraposición a las convenciones mayoritarias, y la medio-centralización de las vocales del castellano de Chile es aparentemente universal.

Por todo lo anterior, los mecanismos sociolingüísticos no pueden dar cuenta de este fenómeno.

\subsubsection{Cambio inducido por el contacto lingüistico}

Como ya se argumentó en el apartado 4.2, no hay evidencias que apoyen la idea de que el actual sistema vocálico chileno sea producto de la retención de un sistema similar de un estadio antiguo de la lengua. Del mismo modo, es esencialmente nula la probabilidad de que una innovación espontánea 
-impulsada o no por supuestas "fuerzas internas" o "factores estructurales" de la lengua castellana- haya cambiado las vocales chilenas de tal modo que terminaran siendo casi idénticas a las del mapudungun, máxime cuando dichas vocales son verdaderas rarezas tipológicas, tal como se arguyó en el apartado 4.3.

Un mecanismo que sí podría explicar las propiedades del sistema vocálico chileno es el contacto con el mapudungun. Esto es precisamente lo que propone la tesis indigenista de Lenz en el caso de otros fenómenos fonológicos, y parece ser plenamente aplicable aquí. Los procesos específicos que este mecanismo sugiere son dos: el mestizaje entre la población hispano-chilena y el pueblo mapuche, por una parte (lo que denominaremos la hipótesis demográfica), y la influencia desproporcionada de las madres y las sirvientas - predominantemente mapuches- en la adquisición de la lengua, por otra. Adicionalmente, Lenz postula que la clase baja chilena es preponderantemente indígena, lo cual aumentaría aún más la probabilidad de que su habla exhiba influencias del mapudungun. Desde luego, Alonso disputa estas ideas con elocuencia y pasión. Sin embargo, durante el último medio siglo, distintas disciplinas científicas han demostrado que el filólogo peninsular estaba profundamente equivocado en estas materias.

\subsubsection{La hipótesis demográfica de Lenz}

Con respecto a la hipótesis demográfica, la existencia en Chile de un proceso de mestizaje a gran escala ha sido comprobada más allá de toda duda por una serie de estudios genéticos. Cruz-Coke y Moreno (1994) analizaron la admixtura indígena del ADN de la población de Santiago y Valparaíso en términos de tres clases sociales. En la primera ciudad, encontraron un $9 \%$ de admixtura indígena en la clase alta, un $30 \%$ en la clase media, y un 59\% en la clase baja; en la segunda ciudad, detectaron un $27 \%, 32 \%$ y $52 \%$ en estas tres clases, respectivamente (Figura 20). Esto demuestra que hubo efectivamente un alto nivel de mestizaje en ambas localidades, las cuales Alonso caracterizó como esencialmente libres de mestizaje.

A la vez, este estudio deja en evidencia que Alonso se equivocó rotundamente al acusar a Lenz de haber malinterpretado el origen étnico de la clase baja de la zona central de Chile: "Lenz estudió exclusivamente la pronunciación de esa región fundamentalmente blanca, y cometió el error de creer de raza india a los 'rotos', que no son más que el pobreterío de los blancos" (1940: 283). Lejos de ser "blancos", los rotos - un término (ahora despectivo) que se refiere a la clase baja urbana de Chile-son profundamente mestizos, tal como señaló Lenz y comprobaron Cruz-Coke y Moreno (1994): en la zona en cuestión, este grupo cuenta con una admixtura indígena promedio de aproximadamente $55 \%$. 
Posteriormente, Rocco et al. (2002) examinaron la admixtura indígena del ADN mitocondrial de la población de Santiago. Este componente genético se hereda exclusivamente vía la línea materna, por lo cual permitió a estos autores determinar que "[e]1 84\% de las mujeres que dieron origen a la población actual de Santiago habrían sido indígenas, mientras que el aporte paterno fue principalmente europeo". Debe señalarse que el mayor componente de esta población indígena corresponde a lo que los autores denominan "indígenas del sur", es decir, mapuches ${ }^{12}$. Este hallazgo comprueba la hipótesis de Lenz de que en el Chile de antaño, los niños habrían aprendido el castellano mayoritariamente de madres y sirvientas mapuches, dado que las mujeres europeas constituían solo un pequeño porcentaje de las madres del país, y un porcentaje aún menor de las sirvientas (con toda probabilidad, cerca de cero, debido a las estructuras de clase que imperaban en la época). Por otra parte, Eyheramendy et al. (2015) llevaron a cabo un estudio que analizó alrededor de 686.000 polimorfismos de nucleótido único en chilenos de todo el país. Sus resultados vuelven a confirmar las hipótesis de Lenz respecto del alto grado de mestizaje y del predominio de las mujeres indígenas en la conformación de la población chilena, esta vez no solo en Santiago y Valparaíso, sino a nivel nacional. El porcentaje de admixtura indígena que esta investigación detectó fue uniformemente alto: $46,15 \%$ en la zona que los autores denominan Norte, $40,43 \%$ en la zona Centro 1 (donde se ubican Santiago y Valparaíso), 42,41\% en la zona Centro $2,49,48 \%$ en la zona Sur 1 y $46,94 \%$ en la zona Sur 2 . Debe señalarse que si bien una parte importante de la población indígena actual de la zona Norte es de origen aimara, existe una población significativa de personas de origen mapuche también.

Finalmente, en un informe no publicado de un estudio de secuenciación genómica realizado para el Ministerio de Salud de Chile, Cifuentes et al. (2015) reportan una admixtura indígena para la población chilena a nivel nacional de 38,7\% en el estrato socioeconómico ABC1 (el más alto), 44,8\% en el C2, 46,2\% en el C3, 49,3\% en el D y $51,6 \%$ en el E (el más bajo) (Figura 20). Estas cifras manifiestan la misma tendencia que detectaron Cruz-Coke y Moreno (1994) -mientras más bajo el estrato socioeconómico, mayor el componente indígena-, pero los porcentajes de admixtura indígena que halló esta investigación son muchísimo mayores en los estratos altos y medios, a la vez que la diferencia entre los extremos socioeconómicos es mucho menor: es de solo 12,9 puntos porcentuales, frente a los 50,0 que

\footnotetext{
12 Si bien los autores dividen los mapuches en tres subgrupos -"mapuches", "pehuenches" y "huilliches"-, éstos son generalmente reconocidos como miembros de una misma etnia, denominada también "mapuche".
} 
informaron Cruz-Coke y Moreno (1994). Esta diferencia seguramente se debe a los importantes avances que logró la disciplina de la genética durante los 21 años que separan los dos estudios.

Aparte de confirmar una vez más la hipótesis de Lenz respecto del mestizaje y de la composición étnica de la clase baja en Chile, estos resultados ponen fin al mito de que la clase alta chilena sería de ascendencia casi exclusivamente europea.

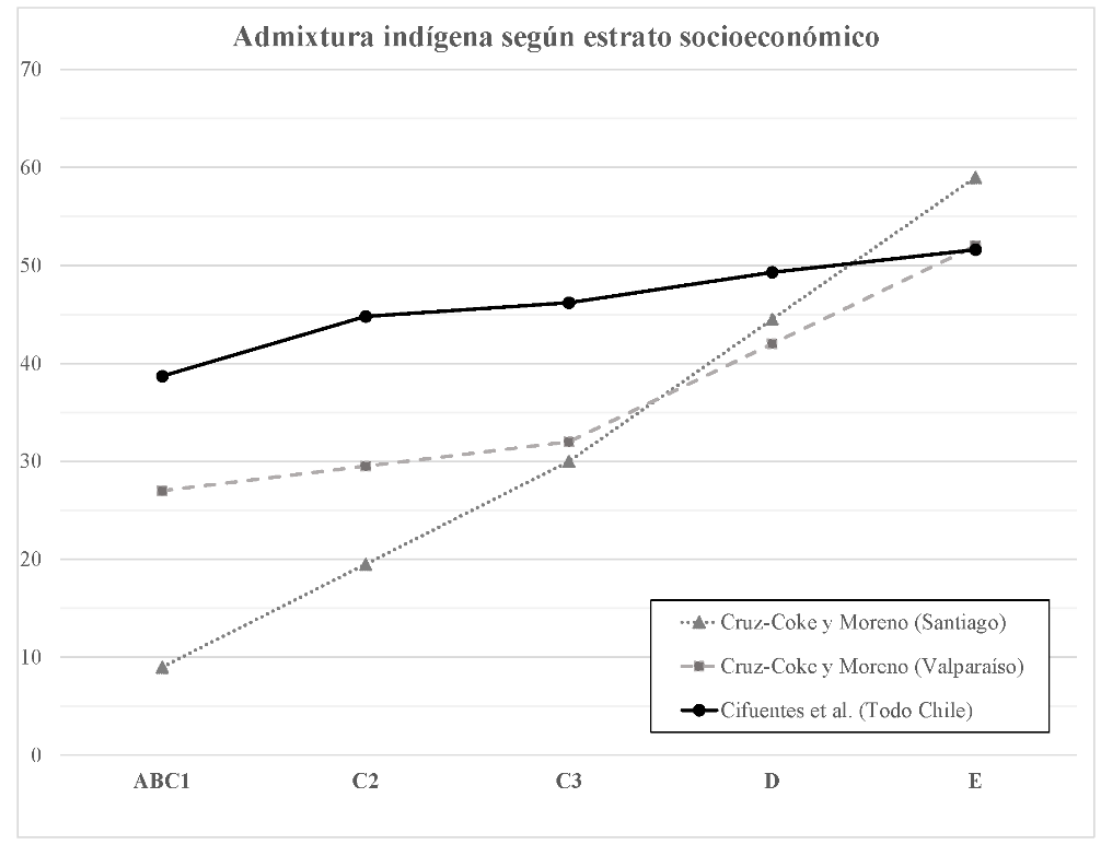

Figura 20. Porcentaje de admixtura indígena del ADN de las poblaciones de Santiago, Valparaíso, y Chile en general, según estrato socioeconómico. Los valores de los estratos C2 y D de Cruz-Coke y Moreno son interpolados de los dos estratos adyacentes.

En resumen, los estudios genéticos de la población chilena han confirmado de manera irrefutable las tres hipótesis de Lenz respecto de la conformación de la población chilena y la transmisión de la lengua: (i) que la población chilena surgió de un mestizaje profundo; (ii) que los miembros del estrato bajo son de proveniencia mayoritariamente indígena; y (iii) que la población femenina de la época fundacional de Chile $-\mathrm{y}$, por ende, las madres y sirvientas que constituyeron la fuente principal de input lingüístico de los niños- fue, en su abrumadora mayoría, indígena. 
Las condiciones demográficas del país fueron, en efecto, extremadamente favorables para que el mapudungun influyera en el castellano de Chile, tanto en su sistema vocálico como en otros aspectos de la lengua.

\subsubsection{El mecanismo de la adquisición de la lengua materna}

Como se señaló en el apartado 1.2, Alonso argumenta que el factor decisivo en la adquisición de la lengua no es la influencia materna, sino la decisión racional y consciente del hablante adulto de adaptar su habla al "ideal de naturaleza espiritual" de la lengua (1940: 283-84). Esta visión, basada en el misticismo del siglo XIX (específicamente, en el concepto del Sprachgeist de Jakob Grimm), ya no tenía cabida en la lingüística internacional en la época de Alonso, pero aún pervivía dentro del hispanismo. Posteriormente, el papel determinante en la adquisición y desarrollo de la lengua de quienes crían a los niños ha sido demostrado por incontables investigaciones realizadas en el marco de la lingüística, la psicología, las ciencias cognitivas y otras disciplinas (véanse, entre muchos otros, Hampson y Nelson 1993; Baumwell, Tamis-LeMonda y Bornstein 1997; Karrass et al. 2002). La influencia materna en la lengua es tan fundamental, de hecho, que se inicia in utero (DeCasper y Spence 1986).

El consenso científico ha dado la razón a Lenz en este tema de manera inequívoca: las personas encargadas de la crianza de los niños - en la sociedad chilena de la época que nos atañe, éstas eran las madres y sirvientas- son determinantes en la adquisición y desarrollo de la lengua. Los ideales espirituales de las lenguas, en cambio, no existen.

\section{CONCLUSIONES}

\subsection{LenZ, Alonso y LA TESIS INDIGENISTA}

Como se ha señalado a lo largo del presente artículo, los argumentos que esgrime Alonso contra la posibilidad de que el mapudungun haya influido en el castellano de Chile son insuficientes (sus opiniones respecto de la realización bilabial de/f/, la realización lámino-alveolar de/t, d, s/ después de / $/$, y el empleo del fonema /t $\int /$ en hipocorísticos y palabras del ámbito familiar, en cuyos casos no existe evidencia suficiente para llegar a conclusión alguna); se basan en información falsa (sus aseveraciones sobre la $/ \mathrm{r} / \mathrm{del}$ mapudungun y la palatalización de las velares / $\mathrm{k}, \mathrm{g}, \mathrm{x} /$ ante /e, i/); son de mala 
fe (su negación de la existencia de $t r$ en el mapudungun, de cuya falsedad no puede sino haber sabido); se derivan del misticismo decimonónico (su apelación al "espíritu de la lengua" como fuerza rectora de la adquisición y desarrollo lingüísticos), y/o están lisa y llanamente equivocados (su tajante negación de la existencia del mestizaje en el centro de Chile, junto con su insistencia en que la clase baja urbana de esta zona es "blanca").

Además, la médula de su argumento general en contra de cualquier posibilidad de influencia indígena en el castellano de Chile se basa en una falacia: la creencia dogmática de que la existencia de un mismo fenómeno en más de una variedad del castellano puede explicarse exclusivamente mediante la homología, es decir, la herencia del rasgo de un ancestro lingüístico común, pese a que existe otro mecanismo -la evolución convergente, mediante la transferencia lingüística entre lenguas- que en muchos casos explica tales fenómenos mejor que la homología, y que se ha documentado desde hace varios siglos.

Puede resultar tentador tratar de justificar la pobreza de los argumentos de Alonso apelando a la idea de que era un hombre de su época, y que como tal reflejaba los prejuicios y la ignorancia propios de ese entonces. Sin embargo, no se observan estos vicios en la argumentación de Lenz, a pesar de que pertenecía a una generación aún más antigua que Alonso. No cabe duda de que el lingüista alemán se equivocó en varias de sus aseveraciones, como por ejemplo, lo relacionado con la aspiración o elisión de /s/ y la espirantización de las oclusivas sonoras. Pero éstos son lo que se podrían denominar "errores honestos", y es difícil imaginar que Lenz no hubiera cambiado sus conclusiones si hubiera contado con datos más completos. Esto, porque la obra de Lenz se destaca permanentemente por la primacía de los datos empíricos por sobre los conceptos previos, por la argumentación escrupulosamente honesta, y por el rigor científico.

El caso de Alonso es distinto. No parece haber sido la falta de conocimientos ni un limitado repertorio argumental lo que determinaron su comportamiento en esta polémica, sino una agenda ideológica informada por el supremacismo ibérico y el racismo. A modo de ejemplo, sus tajantes aseveraciones sobre la supuesta inexistencia del mestizaje en Santiago y el valle central de Chile resultan francamente inconcebibles, dado que visitó la zona -cuya población tiene en promedio un $40,43 \%$ de admixtura indígena (Eyheramendy et al. 2015)- por lo menos cuatro veces: en 1934, 1936, 1941 y 1943 (Torres Caballero 2007). Estas y otras aseveraciones contrafactuales solo pueden explicarse convincentemente como una manifestación del deseo de invisibilizar a los pueblos indígenas en Chile y ocultar su posible aporte al castellano propio de este territorio. Por otra parte, la utilización por Alonso de datos falsos, falacias lógicas y los demás vicios argumentativos 
que ya se han señalado, junto con la campaña de desprestigio que llevó a cabo en contra de Lenz después de su muerte, indican que no buscaba llegar a la verdad, sino que pretendía suprimir a toda costa el conocimiento de fenómenos lingüísticos exclusivamente americanos, y específicamente de origen indígena, para así mantener la ilusión de la homogeneidad y unidad del castellano, junto con el mito de su naturaleza "impoluta" en lo que se refiere a los pueblos indígenas americanos.

\title{
5.2. LA TESIS INDIGENISTA REIVINDICADA
}

La evidencia que proporciona la presente investigación sugiere que la actual configuración del sistema vocálico del castellano de Chile surgió del contacto con el mapudungun. El sistema ha mantenido la estructura fonológica patrimonial, consistente en cinco fonemas, pero aparentemente refonetizó sus alófonos de tal modo que se asemeja más a las vocales del mapudungun que a las de otras variedades del castellano.

Estos resultados reivindican la tesis indigenista de Lenz, pero desde un aspecto de la lengua que él mismo no consideró, que son las vocales. A la vez, tal como se argumenta en el apartado 1.3, varias de las hipótesis de Lenz respecto de las consonantes chilenas parecen ser efectivamente correctas, mientras que otras merecen ser reevaluadas con herramientas y teorías modernas, y sin los prejuicios ponzoñosos que han desincentivado el estudio científico de los fenómenos de contacto en el castellano.

Dado lo anterior, y a la luz del notable acierto de la hipótesis demográfica de Lenz, la cual ha sido comprobada más allá de toda duda por una serie de estudios genéticos, junto con su visionaria propuesta respecto del papel determinante de las personas que crían a los niños en la adquisición y desarrollo de la lengua, sería en extremo provechoso retomar las ideas fundamentales de su tesis indigenista y reanudar la búsqueda de nuevos fenómenos de origen mapuche en el castellano de Chile.

\author{
REFERENCIAS BIBLIOGRÁFICAS
}

Alonso, Amado. 1940. La interpretación araucana de Lenz para la pronunciación chilena. El español en Chile. Trabajos de Rodolfo Lenz, Andrés Bello y Rodolfo Oroz. Traducción, notas y apéndices de Amado Alonso y Raimundo Lida, editado por Amado Alonso y Raimundo Lida, pp. 279-90. Biblioteca de dialectología hispanoamericana, VI. Buenos Aires: Universidad de Buenos Aires, Facultad de Filosofía y Letras, Instituto de Filología. 
1953a. Examen de la teoría indigenista de Rodolfo Lenz [1939]. Estudios lingüísticos: temas hispanoamericanos, editado por Amado Alonso y Raimundo Lida, pp. 332-98. Madrid: Gredos.

1953b. La interpretación araucana de Lenz para la pronunciación chilena. En Estudios lingüísticos: temas hispanoamericanos, editado por Amado Alonso y Raimundo Lida, pp. 279-89. Madrid: Gredos.

1953c. Rodolfo Lenz y la dialectología hispanoamericana. Estudios lingüísticos: temas hispanoamericanos, editado por Amado Alonso y Raimundo Lida, pp. 269-78. Madrid: Gredos.

1967. Algunas cuestiones fundamentales. La base lingüística del español americano. Estudios lingüísticos. Madrid: Gredos.

y Raimundo Lida, eds. 1940. El español en Chile. Trabajos de Rodolfo Lenz, Andrés Bello y Rodolfo Oroz. Biblioteca de dialectología hispanoamericana, VI. Buenos Aires: Facultad de Filosofía y Educación, Universidad de Chile.

Álvarez-Santullano, Pilar. 1986. Descripción fonemática del huilliche: estudio comparativo. Alpha (Osorno) 2: 45-50.

Aronson, Leonor, Hilda M. Furmanski, Leonardo Rufiner y Patricia Estienne. 2000. Características acústicas de las vocales del español rioplatense. Fonoaudiológica 46(2): $12-20$.

Baumwell, Lisa, Catherine S. Tamis-LeMonda y Marc H. Bornstein. 1997. Maternal verbal sensitivity and child language comprehension. Infant Behavior and Development 20(2): 247-258. doi:10.1016/S0163-6383(97)90026-6.

Bernaschina, Vicente. 2013. Rodolfo Lenz, 150 años en disputa con el imperio de la lengua. Universum 28(2): 117-38.

Boersma, Paul y David Weenink. 2016. Praat: Doing phonetics by computer (versión 6.0.14) [en línea]. Disponible en http://www.praat.org/.

Calvo Shadid, Annette y Mario Portilla Chaves. 1998. Variantes retroflejas de / $/ \mathrm{y} / \mathrm{r} /$ en el habla culta de San José. Káñina 22(1): 81-86.

CAStro, AmÉrico. 1924. Metodología de la enseñanza de la lengua i la literatura españolas. Anales de la Universidad de Chile 2: 835-53.

CatriLeo, María. 2010. La lengua mapuche en el siglo XXI. Valdivia: Universidad Austral de Chile.

Chládková, Katerina, Paola Escudero y Paul Boersma. 2011. Context-specific acoustic differences between Peruvian and Iberian Spanish vowels. Journal of the Acoustical Society of America 130(1): 416-28.

Cifuentes, L., E. Llop, L. Herrera, M. Moraga, M. Acuña, S. Berríos, R. Verdugo et al. 2015. Genómica de la población chilena: obtención de perfiles genéticos necesarios en investigación clínica, salud pública y medicina forense. Transferencia de Resultados al Ministerio de Salud. Santiago: FONDEF.

Contreras, Constantino. 1989. Lengua y folklore en la obra de Rodolfo Lenz. Estudios Filológicos 24: 39-53.

Contreras Seitz, Manuel. 2004. El español de Chile en el periodo colonial: Fonética. Osorno (Chile): Universidad de Los Lagos.

Crothers, John. 1978. Typology and universals in vowel systems. En John H. Greenberg, Charles A. Ferguson y Ellen A. Moravcsik (eds.). Universals of Human Language, pp. 93-152. Stanford: Stanford University Press.

Cruz-Coke, Ricardo y Rodrigo S. Moreno. 1994. Genetic epidemiology of single gene defects in Chile. Journal of Medical Genetics 31(9): 702-706.

Cuervo, Rufino José. 1901. El castellano en América. Bulletin Hispanique 3: 35-62. 
DeCasper, Anthony J. y Melanie J. Spence. 1986. Prenatal maternal speech influences newborns' perception of speech sounds. Infant Behavior and Development 9 (2): 133-150. doi:10.1016/0163-6383(86)90025-1.

Disner, SANDra FerRari. 1984. Insights on vowel spacing: results of a language survey. En Patterns of Sounds, editado por Ian Maddieson, pp. 136-55. Cambridge: Cambridge University Press.

Eyheramendy, Susana, Felipe I. Martinez, Federico Manevy, Cecilia Vial y Gabriela M. Repetto. 2015. Genetic Structure Characterization of Chileans Reflects Historical Immigration Patterns. Nature Communications 6 (marzo). doi:10.1038/ncomms 7472

Febres, Andrés. 1765. Arte de la lengua general del reyno de Chile. Lima: Calle de la Encarnación.

Figueroa, Mauricio. 2008. Prestigio de las variantes de /tr/ en la comuna de Concepción. Estudio sociolingüístico. Tesis para optar al grado de licenciado en Educación mención Español. Universidad de Concepción.

Jaime Soto Barba y Marco Ñanculeo. 2010. Los alófonos del grupo consonántico /tr/ en el castellano de Chile. Onomázein 22: 11-42.

Godínez, MANUEL. 1978. A comparative study of some romance vowels. UCLA Working Papers in Phonetics 41: 3-19.

Guion, Susan G. 2003. The Vowel Systems of Quichua-Spanish Bilinguals. Phonetica 60(2): 98-128. doi:10.1159/000071449.

Hampson, June y Katherine Nelson. 1993. The relation of maternal language to variation in rate and style of language acquisition. Journal of Child Language 20(02): 313-342. doi:10.1017/S0305000900008308.

Heggarty, Paul. 2017. Sound Comparisons: Andes [en línea]. Disponible en https:// soundcomparisons.com/Andes (Consulta: 2020-07-17).

HernáNDEZ, Arturo. 1981. Influencia del mapuche en el castellano. Revista Universitaria 5: $111-120$.

IIvonen, AntTI. 1994. A Psychoacoustical Explanation for the Number of Major IPA Vowels. Journal of the International Phonetic Association 24(2): 73-90. doi:10.1017/ S0025100300005089.

Karrass, Jan, Julia M. Braungart-Rieker, Jennifer Mullins y Jennifer Burke Lefever. 2002. Processes in language acquisition: the roles of gender, attention, and maternal encouragement of attention over time. Journal of Child Language 29(03): 519-543. doi:10.1017/S0305000902005196.

Kendall, Tyler y Erik R. Thomas. 2014. Vowels: Vowel Manipulation, Normalization and Plotting in R (versión 1.2-1) [en línea]. Disponible en https://cran.r-project.org/web/ packages/vowels/index.html.

Labov, William. 1994. Principles of Linguistic Change, vol. 1: Internal Factors. Oxford: Blackwell.

LenZ, Rodolfo. 1912. Los elementos indios del castellano de Chile. Actas del XVII Congreso Internacional de Americanistas, pp. 232-42. Buenos Aires: Imprenta de Coni Hnos.

1940a. Estudios Chilenos I-VII [1892-93]. El español en Chile. Trabajos de Rodolfo Lenz, Andrés Bello y Rodolfo Oroz, editado por Amado Alonso y Raimundo Lida, pp. 84-208. Biblioteca de dialectología hispanoamericana, VI. Buenos Aires: Facultad de Filosofía y Letras de la Universidad de Buenos Aires.

1940b. Para el conocimiento del español de América [1893]. El español en Chile. Trabajos de Rodolfo Lenz, Andrés Bello y Rodolfo Oroz, editado por Amado Alonso y Raimundo Lida, pp. 209-58. Biblioteca de dialectología hispanoamericana, VI. Buenos Aires: Facultad de Filosofía y Educación, Universidad de Chile. 
LiLJENCRANTS, JOHAN Y BJÖRn LindBLOM. 1972. Numerical simulation of vowel quality systems: The role of perceptual contrast. Language 48: 839-62.

LindBlom, BJöRn. 1986. Phonetic universals in vowel systems. Experimental Phonology, editado por John J. Ohala y Jeri J. Jaeger, pp. 13-44. Orlando: Academic Press.

Lindstedt, Jouko. 2000. Linguistic Balkanization: Contact-Induced Change by Mutual Reinforcement. Studies in Slavic and General Linguistics 28: 231-46.

LIPSKI, JoHn. 1994. Latin American Spanish. London: Longman.

MalvestitTi, Marisa. 1993. Castellano mapuchizado en la Línea Sur. Aproximaciones. Actas de las Primeras Jornadas de Etnolingüística, pp. 137-44. Rosario: Universidad Nacional de Rosario.

Martínez Celdrán, Eugenio. 1995. En torno a las vocales del español: análisis y reconocimiento. Estudios de Fonética Experimental 7: 195-218.

MenÉndez Pidal, Ramón. 1918. La lengua española. Hispania 1(1): 1-14.

1947. La unidad del idioma. Castilla, la tradición, el idioma, pp. 171-218. Buenos Aires: Espasa-Calpe.

Morales Pettorino, Félix y Óscar Quiroz. 2010a. Nuevo Diccionario Ejemplificado de Chilenismos. Edición refundida y actualizada. Suplemento. Volumen 1 ( 9 del DECh). Valparaíso: Puntángeles.

2010b. Nuevo Diccionario Ejemplificado de Chilenismos. Edición refundida y actualizada. Suplemento. Volumen 2 (10 del DECh). Valparaíso: Puntángeles.

y Patricia Arancibia. 2006a. Nuevo diccionario ejemplificado de chilenismos y de otros usos diferenciales del español de Chile. Volumen 1 (6 del DECh). A-E. Valparaíso: Puntángeles.

Morales Pettorino, Félix, Óscar Quiroz y Patricia Arancibia. 2006b. Nuevo diccionario ejemplificado de chilenismos y de otros usos diferenciales del español de Chile. Volumen 2 (7 del DECh). F-Pe. Valparaíso: Puntángeles.

2006c. Nuevo diccionario ejemplificado de chilenismos y de otros usos diferenciales del español de Chile. Volumen 3 (8 del DECh). Pg-Z. Valparaíso: Puntángeles.

y Juan Peña Álvarez. 1984. Diccionario Ejemplificado de Chilenismos y de otros usos diferenciales del español de Chile. Volumen 1. A-Caz. Valparaíso: Academia Superior de Ciencias Pedagógicas.

y JuAn Peña Álvarez. 1985. Diccionario Ejemplificado de Chilenismos y de otros usos diferenciales del español de Chile. Volumen 2. CC-Grup. Valparaíso: Academia Superior de Ciencias Pedagógicas.

Morales Pettorino, Félix, Óscar Quiroz y Juan Peña Álvarez. 1986. Diccionario Ejemplificado de Chilenismos y de otros usos diferenciales del español de Chile. Volumen 3. Gua-Peq. Valparaíso: Academia Superior de Ciencias Pedagógicas.

1987. Diccionario Ejemplificado de Chilenismos y de otros usos diferenciales del español de Chile. Volumen 4. Per-Z, suplemento, bibliografía. Valparaíso: Academia Superior de Ciencias Pedagógicas.

1998. Diccionario Ejemplificado de Chilenismos y de otros usos diferenciales del español de Chile. Volumen 5. A-Z. Valparaíso: Universidad de Playa Ancha de Ciencias de la Educación.

Morimoto, Yoshinaru. 1988. The five vowels of Castilian and Japanese: a spectrographic analysis. Sophia Linguistica 23-24: 181-92.

Oroz, Rodolfo. 1966. La lengua castellana en Chile. Santiago: Universidad de Chile.

Quilis, ANTONiO y MANUEl EsGueva. 1983. Realización de los fonemas vocálicos españoles en posición fonética normal. Estudios de fonética I, editado por Manuel Esgueva y Margarita Cantarero, pp. 137-252. Madrid: Consejo Superior de Investigaciones Científicas, Instituto Miguel de Cervantes. 
R. Core Team. 2016. R: A language and environment for statistical computing (versión 3.2.3) [en línea]. Vienna: R Foundation for Statistical Computing. Disponible en https:// www.R-project.org/.

Rabanales, Ambrosio. 2002. Rodolfo Lenz. Onomázein 7: 161-81.

Rivadeneira, Marcela. 2009. El voseo en medios de comunicación de Chile. Descripción y análisis de la variación dialectal y funcional [en línea]. Disponible en http://www.tdx. cat/handle/10803/7510.

Rocco, Paola, Carmen Morales G., Mauricio Moraga V., Juan Francisco Miquel P., Flavio Nervi O., Elena Llop R., Pilar Carvallo S. y Francisco Rothhammer E. 2002. Composición genética de la población chilena: Distribución de polimorfismos de DNA mitocondrial en grupos originarios y en la población mixta de Santiago. Revista Médica de Chile 130(2): 125-31. doi:10.4067/S0034-98872002000200001.

Rosenblat, Ángel. 1945. La población indígena de América desde 1492 hasta la actualidad. Buenos Aires: Institución Cultural Española.

SAdowsky, Scotт. 2015. Variación sociofonética de las consonantes del castellano chileno. Sociolinguistic Studies 9(1): 71-92. doi:10.1558/sols.v9i1.19927.

2016. The socioeconomic and gender stratification of Chilean Spanish vowel allophones. En New Ways of Analyzing Variation (NWAV) 45. Vancouver: Simon Frasier University.

2021. EMIS: Sistema de estratificación socioeconómica para la investigación lingüística [The EMIS Socioeconomic Stratification System for Linguistic Research]. En Chilean Spanish Linguistics: Studies on Variation, Innovation, Contact, and Identity, editado por Brandon M. A. Rogers y Mauricio Figueroa Candia. Wilmington, DE: Vernon Press.

María José Aninao, María Isabel Cayunao y Paul Heggarty. 2015. Huilliche: ¿geolecto del mapudungun o lengua propia? Una mirada desde la fonética y la fonología de las consonantes. Lingüística indígena sudamericana: aspectos descriptivos, comparativos $y$ areales, editado por Ana Fernández Garay y Alejandra Regúnaga, pp. 23-51. Archivo de Lenguas Indoamericanas. Buenos Aires: Instituto de Lingüística, Facultad de Filosofía y Letras, Universidad de Buenos Aires.

y Paul Heggarty. 2017. Sound Comparisons: Mapudungun [en línea]. Disponible en https://soundcomparisons.com/Mapudungun (Consulta: 2020-07-17).

Héctor Painequeo, Gastón Salamanca y Heriberto Avelino. 2013. Illustrations of the IPA: Mapudungun. Journal of the International Phonetic Association 43(1): 87-96. doi:10.1017/S0025100312000369.

y GaStón SALAMANCA. 2011. El inventario fonético del español de Chile: principios orientadores, inventario provisorio de consonantes y sistema de representación (AFI-CL). Onomázein 24(2): 61-84.

Salamanca, Gastón. 1997. Fonología del pehuenche hablado en el Alto Bío-Bío. RLA. Revista de Lingüística Teórica y Aplicada 35: 113-24.

y Elizabeth Quintrileo. 2009. El mapuche hablado en Tirúa: Fonemas segmentales, fonotaxis y comparación con otras variedades. RLA. Revista de Lingüística Teórica y Aplicada 47(1): 13-35.

Salas, Adalberto. 1976. Esbozo fonológico del mapudungu, lengua de los mapuče o araucanos de Chile central. Estudios Filológicos 11: 143-53.

1992. El componente indoamericano en la identidad sociocultural chilena. Una presentación etnolingüística. Acta Literaria 17: 11-24.

1996. El indigenismo romántico. Examen etnolingüístico de una retórica en torno al quinto centenario. Onomázein 1: 139-51. 
Schwartz, Jean-Luc, Louis-Jean Boë, Nathalie Vallée y Christian Abry. 1997a. Major Trends in Vowel System Inventories. Journal of Phonetics 25: 233-53. 233-53.

1997b. The Dispersion-Focalization Theory of Vowel Systems. Phonetics 25:

Silva-Corvalán, Carmen. 2001. Sociolingüistica y pragmática del español. Washington: Georgetown University Press.

Tapia, Mónica, y Humberto Valdivieso. 1997. La palatalización de las velares. Análisis acústico. Onomázein 2: 135-49.

Tomić, Olga MišESKa. 2008. An integrated areal-typological approach: Local convergence and morphosyntactic features in the Balkan Sprachbund. From linguistic areas to areal linguistics, editado por Pieter Muysken, pp. 181-219. Amsterdam/Philadelphia: John Benjamins.

Torres Caballero, Vidal. 2007. Un discurso chileno de Amado Alonso. Cauce 30: 473-80.

Valencia, Alba. 1993. El legado de tres maestros: Lenz, Oroz y Rosales. RLA. Revista de Lingüística Teórica y Aplicada 31: 137-62. 